\title{
The response and recovery of the Arabidopsis thaliana transcriptome to phosphate starvation
}

Jongchan $\mathrm{WoO}^{1 \dagger}$, Cameron Ross MacPherson ${ }^{1,4+}$, Jun Liu' ${ }^{1}$, Huan Wang ${ }^{1,3}$, Takatoshi Kiba ${ }^{1}$, Matthew A Hannah², Xiu-Jie Wang ${ }^{3}$, Vladimir B Bajic ${ }^{4}$ and Nam-Hai Chua ${ }^{1 *}$

\begin{abstract}
Background: Over application of phosphate fertilizers in modern agriculture contaminates waterways and disrupts natural ecosystems. Nevertheless, this is a common practice among farmers, especially in developing countries as abundant fertilizers are believed to boost crop yields. The study of plant phosphate metabolism and its underlying genetic pathways is key to discovering methods of efficient fertilizer usage. The work presented here describes a genome-wide resource on the molecular dynamics underpinning the response and recovery in roots and shoots of Arabidopsis thaliana to phosphate-starvation.
\end{abstract}

Results: Genome-wide profiling by micro- and tiling-arrays (accessible from GEO: GSE34004) revealed minimal overlap between root and shoot transcriptomes suggesting two independent phosphate-starvation regulons. Novel gene expression patterns were detected for over 1000 candidates and were classified as either initial, persistent, or latent responders. Comparative analysis to AtGenExpress identified cohorts of genes co-regulated across multiple stimuli. The hormone ABA displayed a dominant role in regulating many phosphate-responsive candidates. Analysis of co-regulation enabled the determination of specific versus generic members of closely related gene families with respect to phosphate-starvation. Thus, among others, we showed that PHR1-regulated members of closely related phosphate-responsive families (PHT1;1, PHT1;7-9, SPX1-3, and PHO1;H1) display greater specificity to phosphate-starvation than their more generic counterparts.

Conclusion: Our results uncover much larger, staged responses to phosphate-starvation than previously described. To our knowledge, this work describes the most complete genome-wide data on plant nutrient stress to-date.

Keywords: Phosphate starvation, Response and recovery, Roots and shoots, Organ specific, Whole seedling, Initial, Persistent, and Latent expression patterns, Functional analysis, Comparative analysis with AtGenExpress, Micro-array and tiling-array, Hydroponic culture

\section{Background}

Phosphorus is one of the most important macronutrients in crop fertilizers [1,2]. Although it is required in only small quantities [3] most crop plants require inorganic forms of phosphorous such as phosphate $\left(\mathrm{P}_{\mathrm{i}}\right)$ that is not readily available in many soil conditions $[4,5]$. Because of $\mathrm{P}_{\mathrm{i}}$-limiting stress, $\mathrm{P}_{\mathrm{i}}$ fertilizers are used in agriculture to elevate soil $P_{i}$ concentrations to increase crop productivity [4]. However, over-application of $P_{i}$ fertilizers has led to

\footnotetext{
* Correspondence: chua@mail.rockefeller.edu

${ }^{\dagger}$ Equal contributors

'Laboratory of Plant and Molecular Biology, The Rockefeller University, New York 10065, NY, USA

Full list of author information is available at the end of the article
}

run-off of excess $P_{i}$ into waterways damaging ecosystems [6-8]. Therefore, there is economic and ecological impetus underlying research into plant $P_{i}$ signaling pathways with the expectation that results from such work may help to develop crop plants with enhanced $P_{i}$ use efficiency, thereby mitigating the unwarranted, excessive application of $P_{i}$ fertilizers.

Whereas many researchers have studied $P_{\mathrm{i}}$ signaling in the model plant Arabidopsis thaliana, it is only recently that high-throughput technologies have been applied to address this issue [9-14]. To date, a limited amount of genome-wide data is available and there is no one dataset that can serve as a reference for comparison in studies on $\mathrm{P}_{\mathrm{i}}$-signaling. Our ability to relate one genome-wide study to

\section{Biomed Central}


another is, therefore, constrained by insufficient data. Here, we aimed to construct a referable dataset by recording and characterizing the response and recovery of Arabidopsis thaliana's whole genome transcriptome to $\mathrm{P}_{\mathrm{i}}$ starvation $\left(\mathrm{P}_{\mathrm{i}}^{\text {starv }}\right)$ at a higher resolution than previously reported.

Previous studies have implicated common sets of differentially regulated genes during related $\mathrm{P}_{\mathrm{i}}^{\text {starv }}$ treatments but a large degree of variation exists among independent studies (see Additional file 1). Several factors may contribute to this observed variation: (1) Different methodologies were used to manipulate $\mathrm{P}_{\mathrm{i}}$ concentrations in the local environment; (2) Different tissues, organs, and plant species were studied, that may implement different $\mathrm{P}_{\mathrm{i}}$-sensing and gene response circuitry; (3) Previous work did not analyze independent responses of roots and shoots on a genomewide scale; (4) Due to natural $\mathrm{P}_{\mathrm{i}}$-reservoirs in plant samples it is difficult to determine the duration of starvation treatment; (5) There is a lack of a comprehensive study serving as a basic reference.

To address the above-mentioned issues we aimed to not only identify novel genetic components in the Arabidopsis $\mathrm{P}_{\mathrm{i}}^{\text {starv }}$ response but also provide results that can serve as a reference for future investigations. To this end, we designed experiments to evaluate differential gene expression separately in roots and shoots of plants subjected to $\mathrm{P}_{\mathrm{i}}^{\text {starv }}$ ("response" phase) followed by return to replete conditions ("recovery" phase). In total, we analyzed 18 microand 18 tiling-arrays consisting of the following sample structure: 3 biological replicates sampled from 2 organs (roots and shoots), each exposed to 3 conditions (mock $\left(\mathrm{P}_{\mathrm{i}}^{\text {mock }}\right)$, starvation $\left(\mathrm{P}_{\mathrm{i}}^{\text {starv }}\right)$, and replete $\left.\left(\mathrm{P}_{\mathrm{i}}^{\text {replete }}\right)\right)$. Gene response was evaluated by contrasting $\mathrm{P}_{\mathrm{i}}^{\text {starv }}$ against $\mathrm{P}_{\mathrm{i}}^{\text {mock }}$, whereas gene recovery was calculated by contrasting $\mathrm{P}_{\mathrm{i}}^{\text {replete }}$ versus $\mathrm{P}_{\mathrm{i}}^{\text {starv }}$ samples. In this way, we aimed to address the first three issues by providing a common reference for the analysis of organ-specific response and recovery. To address (4) we provided molecular evidence to demonstrate that genes did indeed respond to, and subsequently recovered from, $\mathrm{P}_{\mathrm{i}}^{\text {starv }}$. We addressed (5), in part, as our experimental model generated a high-quality dataset by analyzing both response-and-recovery data from plants conditioned in the same environment using both the ATH1 microarray and the tiling-array platform for transcriptome analysis.

Our data indicated a dramatic difference in the molecular responses of roots and of shoots both during and post $\mathrm{P}_{\mathrm{i}}^{\text {starv }}$. We showed that significantly different regulons are involved in $\mathrm{P}_{\mathrm{i}}^{\text {starv }}$ in both a time and organ dependent manner. Furthermore, in comparative studies with micro-array data generated by the AtGenExpress initiative we developed a method for the determination of specific versus generic members of closely related gene families with respect to $\mathrm{P}_{\mathrm{i}}^{\text {starv }}$.
Being a genome-wide study, we identified many genes previously unknown to respond to and/or recover from $\mathrm{P}_{\mathrm{i}}^{\text {starv }}$. To further verify the specificity of their functions we conducted literature surveys on possible co-regulation by other stresses of many candidates. We believe that our work collectively describes the highest resolution of genome-wide data available to the community to date. The accession code, GSE34004, may be used to access the micro- and tiling-array data from the Gene Expression Omnibus (GEO).

\section{Results}

\section{Experimental design and quality assessment}

We incorporated organ specific $\mathrm{P}_{\mathrm{i}}^{\text {starv }}$ treatment and recovery into one set of experiments. Briefly, we grew seedlings in $\mathrm{P}_{\mathrm{i}}$ sufficient media for 20 days, followed by 10 days in $P_{i}$ deficient $\left(P_{i}^{\text {starv }}\right)$ or sufficient $\left(P_{i}^{\text {mock }}\right)$ media to measure gene expression response. Plants grown in $\mathrm{P}_{\mathrm{i}}$ deficient media were then transferred to $P_{i}$ sufficient media for an additional 3 days $\left(\mathrm{P}_{\mathrm{i}}^{\text {replete }}\right)$ for recovery. Roots and shoots were separately collected from various plant samples in 3 replicate experiments. By considering three treatments $\left(\mathrm{P}_{\mathrm{i}}^{\text {mock }}, \mathrm{P}_{\mathrm{i}}^{\text {starv }}\right.$, and $\left.\mathrm{P}_{\mathrm{i}}^{\text {replete }}\right)$ we uncovered genes with basal expression during response and recovery, genes that initially responded to $\mathrm{P}_{\mathrm{i}}^{\text {starv }}$, genes that persisted (did not recover) in their initial response during recovery and genes that latently responded during the recovery phase only. These 4 states allowed us to define 9 classes of gene expression patterns (Table 1), and by comparing root and shoot responses, we were able to observe up to 81 $\left(9^{\text {root }} \times 9^{\text {shoot }}\right)$ classes describing organ-specific or -common gene expression patterns (Figure 1i).

To increase confidence in the observed changes, we used two independent platforms to detect genomewide expression changes. We first hybridized all cDNA samples to Affymetrix ATH1 micro-arrays. After having determined each chip to be of sufficient quality we continued to detect differentially regulated genes during response $\left(\mathrm{P}_{\mathrm{i}}^{\text {starv }} / \mathrm{P}_{\mathrm{i}}^{\text {mock }}\right)$ and recovery $\left(\mathrm{P}_{\mathrm{i}}^{\text {replete }} /\right.$ $\mathrm{P}_{\mathrm{i}}^{\text {stary }}$ ) (see Additional file 2). Subsequently, we used principal component analysis (PCA) to analyze the orthogonal relationship between gene response and recovery, and between roots and shoots (Figure 2a,b). Indeed, where the $1^{\text {st }}$ PC likely accounted for broad variations, the $2^{\text {nd }}$ and $3^{\text {rd }}$ PCs captured true biological phenomena. For example, the $2^{\text {nd }} \mathrm{PC}$ accounted for $12 \%$ of the total variation (Figure 2a) and clearly distinguished between root and shoot samples (Figure 2b-xAxis); and, the $3^{\text {rd }}$ PC highlighted differences between $\mathrm{P}_{\mathrm{i}}^{\text {mock }}, \mathrm{P}_{\mathrm{i}}^{\text {starv }}$, and $\mathrm{P}_{\mathrm{i}}^{\text {replete }}$ treatments (Figure 2b-yAxis). Significantly, according to the $3^{\text {rd }} \mathrm{PC}, \mathrm{P}_{\mathrm{i}}^{\text {mock }}$ and $\mathrm{P}_{\mathrm{i}}^{\text {replete }}$ treatments were closely related in both roots and shoots indicating recovery from $\mathrm{P}_{\mathrm{i}}^{\text {starv }}$ in both organs. 
Table 1 Response-and-recovery classification scheme for loci

\begin{tabular}{|c|c|c|c|c|c|c|}
\hline \multirow[t]{2}{*}{ Class } & \multirow[t]{2}{*}{ Code } & \multicolumn{2}{|c|}{ Response } & \multicolumn{2}{|c|}{ Recovery } & \multirow[t]{2}{*}{ Cartoon representation } \\
\hline & & p-Value* & $\log _{2}(F C)$ & p-Value* & $\log _{2}(\mathrm{FC})$ & \\
\hline Basal Response & BAR & \multicolumn{2}{|c|}{ no change } & \multicolumn{2}{|c|}{ no change } & + \\
\hline Continuous Positive Response & CPR & $\leq 0.001$ & + & $\leq 0.001$ & + & 4 \\
\hline
\end{tabular}

Initial Positive Response

Persistent Positive Response

Latent Positive Response

Continuous Negative Response

Initial Negative Response

Persistent Negative Response

Latent Negative Response
IPR

PPR

$\leq 0.001$

LPR

no change

$\leq 0.001$

INR

$\leq 0.001$

PNR

$\leq 0.001$

- $\leq 0.001$

$\leq 0.001$

no change

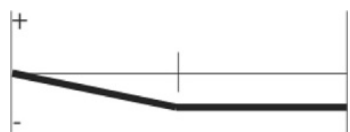

LNR no change
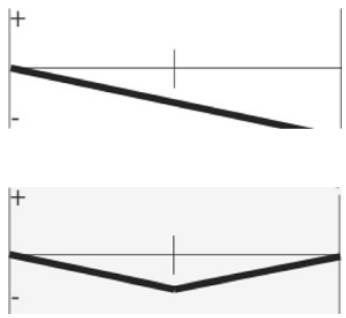

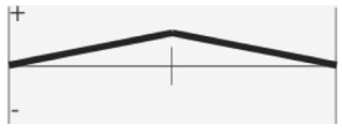

no change
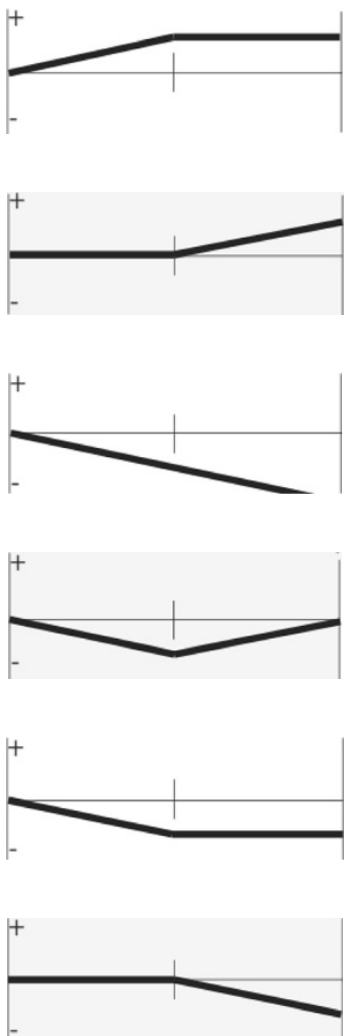

By table headings: (Class) All loci are binned into 1 of 9 response-and-recovery classes; (Code) Classes are given a 3 letter code for convenience. (Response) The

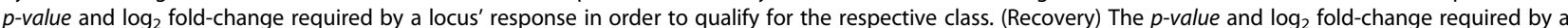
locus' recovery in order to qualify for the respective class. A "no change" is indicated if the $p$-value is not less than or equal to 0.001 . (Cartoon Representation) A cartoon diagram indicating the general expression pattern captured by the class.

To increase confidence in our data we hybridized identical cDNA libraries to Affymetrix tiling-arrays 1.0R, which were processed using cisgenome software [15]. We initially evaluated data parity between the two platforms by calculating correlation of fold-change between probe-sets present on the ATH1 arrays and their corresponding probes on the tiling-arrays 1.0R. The correlation between the two platforms was above 0.8 for the rootresponse, root-recovery, leaf-response and leaf-recovery (Figure 2c). In addition, we confirmed transcript levels of 


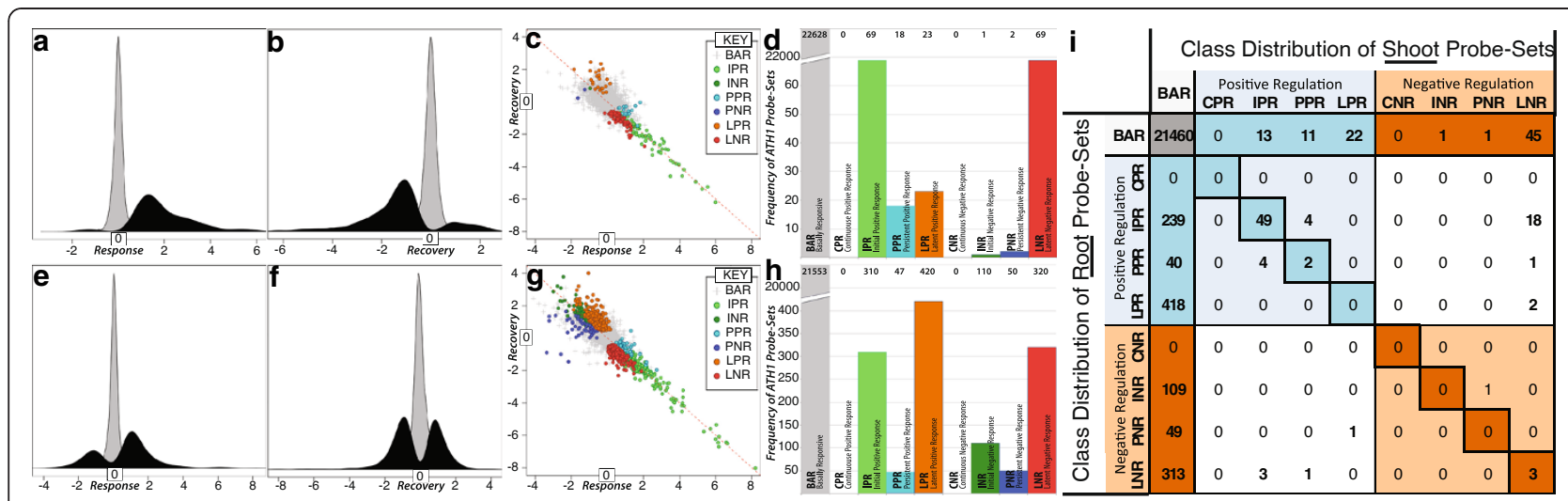

Figure 1 The distribution of probe-sets across tissues and response-and-recovery classes. Subfigures (a), (b), (e), and (f) display the relative distribution (no $y$-axis) of fold-change values ( $\log _{2}$ ) for significantly (black curve) and non-significantly (grey curve) regulated probe-sets in shoot $(\mathbf{a}, \mathbf{b})$ and root $(\mathbf{e}, \mathbf{f})$ for both response $(\mathbf{a}, \mathbf{e})$ and recovery $(\mathbf{b}, \mathbf{f}) .(\mathbf{c}, \mathbf{g})$ Dot plot of fold-change values for response (x-axis) against recovery ( $y$-axis) from shoot $(\mathbf{c})$ and root $(\mathbf{g})$ samples. Probe-sets tend to recovery as is evident by their trend (line of full recovery, dotted red line, $y=-x)$. Significantly regulated probe-sets are colored according to their response-and-recovery classification (Table 1). (d, $\mathbf{h})$ Histogram of probe-set counts (y-axis) according to response-and-recovery classes (Table 1) for shoot (d) and root (h). (i) Table showing the intersection between shoot (columns) and root (rows) response-and-recovery classes. The top leftmost cell being a count of probe-sets neither responsive in shoot nor root. The first column and row being counts of loci uniquely regulated by root and shoot, respectively. The diagonal being counts of ubiquitously regulated probe-sets. Positive and negative regulation is denoted by a blue and red background, respectively. Whereas, probe-sets differentially regulated between shoot and root are denoted using white backgrounds.

37 genes selected from both platforms by quantitative reverse transcriptase PCR (qRT-PCR, see Additional file 3).

\section{Novel $\mathrm{P}_{\mathrm{i}}$-signaling patterns observed among genes involved in $\mathrm{P}_{\mathrm{i}}^{\text {starv }}$ \\ Response-and-recovery gene expression patterns in roots and shoots}

Arabidopsis roots displayed several novel responses to $\mathrm{P}_{\mathrm{i}}^{\text {starv }}$ not observed in previous genome-wide studies. Several previous studies have each independently identified gene sets that initially respond to $[9,11,12]$ or recover from $\mathrm{P}_{\mathrm{i}}^{\text {starv }}[10]$. However, we were able to additionally identify genes that persisted in their expression during the 3-day recovery period and others that latently responded to $\mathrm{P}_{\mathrm{i}}^{\text {starv }}$ during recovery. Moreover, we were able to characterize these responses in an organspecific manner. A total of 1,257 genes detected by ATH1 probe-sets (henceforth referred to as gene/s) were differentially expressed in roots during either starvation or recovery. Table 1 highlights the criteria used to subclassify each of the 1,257 genes. A large proportion of root-responsive genes $(310, \approx 25 \%)$ fell into the "Initial Positive Response" class (IPR). These genes were significantly up-regulated during starvation but returned to basal levels after recovery (Figure 1e,f,g,h). One hundred and ten genes $(\approx 8 \%)$ were negatively regulated, falling into the "Initial Negative Response" class (INR). By contrast, 47 and 50 genes continued to be up- ("Persistent Positive Response", PPR) or down-regulated ("Persistent Negative Response", PNR), respectively, during recovery.
A significant proportion of the genes (58\%) responded to recovery only after an initial priming by $\mathrm{P}_{\mathrm{i}}^{\text {starv }}$. We classified these latent genes into either the "Latent Positive Response" (LPR; 420 genes) or "Latent Negative Response" (LNR; 320 genes) class. Thus, the latent response of 740 genes (LPR + LNR) was of equal relevance to $\mathrm{P}_{\mathrm{i}}$-signaling as genes of the initial and persistent starvation responses combined (517 genes from IPR, INR, PPR, and PNR). However, as observed in Figure 1g, latently responsive genes (red/orange) are generally regulated to a lesser extent (fold-change) than initially responsive genes (dark-green/light-green).

For shoots, using the same criteria to identify differentially expressed genes as in roots (Table 1), we classified 182 genes into response-and-recovery classes (Figure 1a, b,c,d). Of these 182 genes, $69(\approx 38 \%)$ were classified as IPR whereas only 1 was determined to be INR. Briefly, we classified the remaining 112 genes as follows: 18 PPR and 2 PNR; and, 23 LPR and 69 LNR. Other than the large LPR response in roots (Figure $1 \mathrm{~h}$ ), the distribution of gene numbers between root and shoot classes were similar, with the number of latently responsive genes (92 genes) approximately equal to those of the initial and persistent responses combined (90 genes). In addition, we noted that shoot tissues initially up-regulated $48 \%$ of all responsive genes and the remainder were latently down-regulated in shoots. Hence, shoot tissues show a distinct shift in gene expression patterns, from an almost absolute initial positive response to a similarly strong latent negative response. 


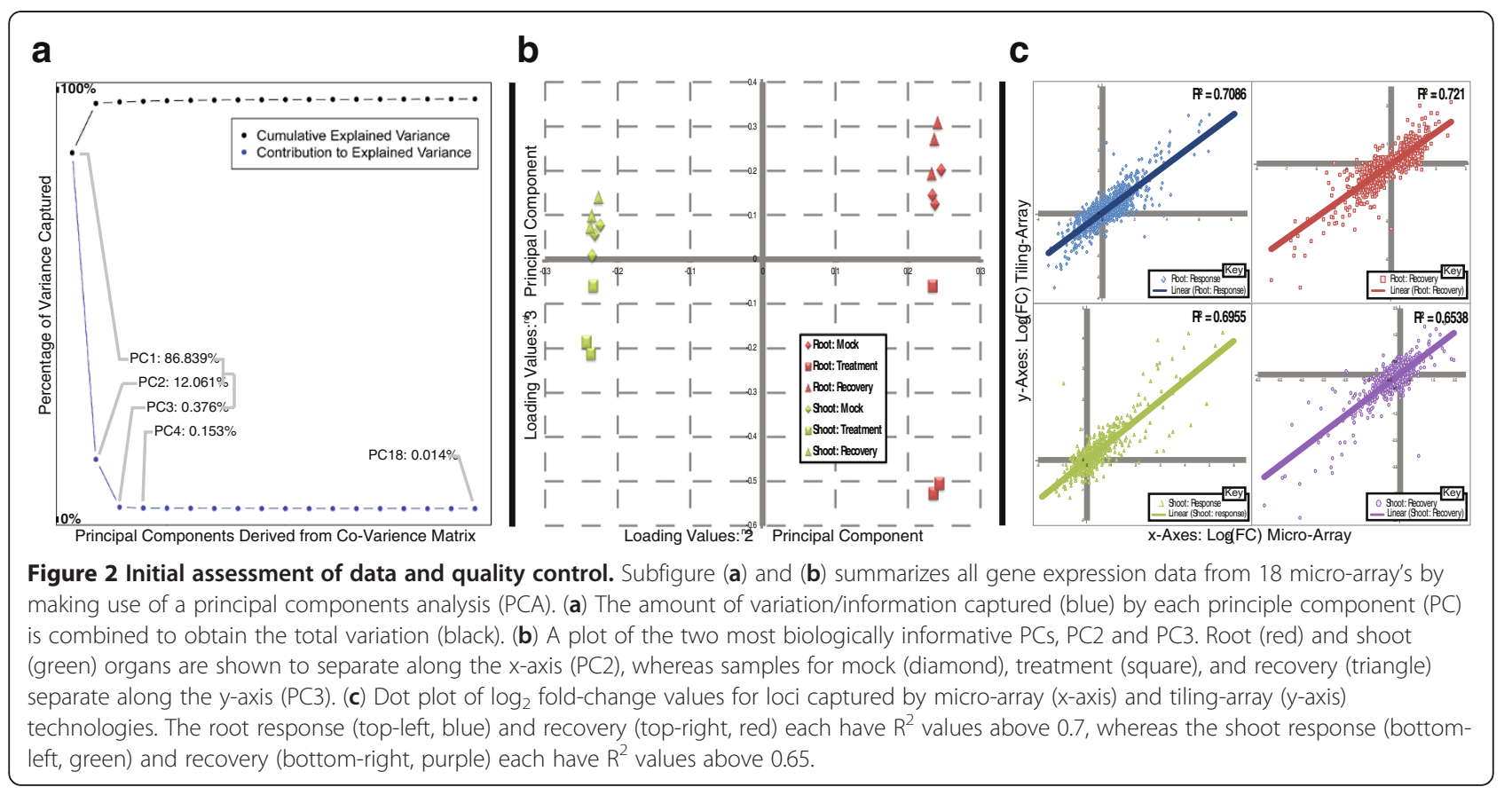

\section{Gene expression in roots and shoots recover from $P_{i}^{\text {starv }}$} after 3 days in replete conditions

Most of the significantly expressed genes, during the initial shoot (Figure 1a-black) and root (Figure 1e-black) responses, returned to basal expression levels after a 3 day recovery in $\mathrm{P}_{\mathrm{i}}$-sufficient conditions $\left(\mathrm{P}_{\mathrm{i}}^{\text {replete }}\right)$. This is indicated by the general trend that genes had to spread across the $y=-x$ axis (Figure 1c,g - dashed red line), i.e. the axis of full-recovery. We note that of the 9 response-and-recovery classes, 2 were neither observed in shoots nor roots. These two undetected classes, "Continuous Positive Response" (CPR) and "Continuous Negative Response" (CNR) described genes that responded significantly and in the same manner during both responseand-recovery phases (Table 1). The absence of these classes in our dataset, together with the general trend of our data and the expression profile of $\mathrm{P}_{\mathrm{i}}$-starvation responsive noncoding RNAs IPS1, miR399, and miR827 (see Additional file 4), confirmed that a 3-day period in $\mathrm{P}_{\mathrm{i}}$ sufficient media was a suitable choice for the recovery period.

\section{Co-expression versus organ specific gene expression patterns}

Both roots and shoots responded to $\mathrm{P}_{\mathrm{i}}^{\text {starv }}$ to varying degrees by differentially regulating initial and persistently responsive genes. $\mathrm{P}_{\mathrm{i}}$-signaling cascades were initiated in anticipation of $\mathrm{P}_{\mathrm{i}}^{\text {replete }}$ conditions, as observed by genes in the latently responsive class. The root response included 89 genes that were also differentially regulated among a total of 182 shoot responsive genes (Figure 1i-all rows and columns except the first). Yet, both organs displayed characteristic gene expression patterns. Furthermore, roots accounted for $87 \%$ of the combined $\mathrm{P}_{\mathrm{i}}$-responsive genes in both organs. Consideration of the root/shoot response without the 89 ubiquitously regulated genes uncovered at least 2 tissue-specific and $\mathrm{P}_{\mathrm{i}}$-sensitive regulons. The 89 coregulated genes may be involved in systemic $\mathrm{P}_{\mathrm{i}}$-signaling as $60 \%$ of these putative systemic-regulators were differentially regulated in the same manner in both organs (Figure 1idiagonal). Thibaud et al. (2010) identified 42 systemically regulated genes of which 16 where basally regulated and 14 were considered to be regulated in both our root and shoot datasets. Of the remaining 35 genes in our study (40\%), 8 and 1 were generally up- and down-regulated in roots and shoots, respectively; whereas, 26 genes displayed antagonistic behavior between the two organs.

The classification of response-and-recovery into 9 distinct classes reflected the molecular diversity in $\mathrm{P}_{\mathrm{i}}$-signaling during $\mathrm{P}_{\mathrm{i}}^{\text {starv }}$. The independent analysis of roots and shoots has aided in the identification of systemic versus organ-specific responses. Differential regulation of systemic and organ-specific genes is indicative of function related to the $\mathrm{P}_{\mathrm{i}}^{\text {starv }}$ response. In the following, we present correlations between observed classes and annotations among public databases and current literature.

\section{The response and recovery of genes absent from the micro-array platform}

A clear advantage of the 1.0R tiling-array platform over the ATH1 micro-array is the detection of transcripts derived from genomic regions not covered by the microarray's optimized probes. Indeed, TAIR8 has annotations for 26,956 nuclear protein-coding genes (AGI identifiers, PUBMedID: 22140109). Of these, 21,912 (81\%) genes are 
represented by probes on the ATH1 micro-array. With this in mind we set out to characterize the transcriptional response and recovery to $\mathrm{P}_{\mathrm{i}}^{\text {starv }}$ of the remaining 5,044 genes undetectable by the ATH1 micro-array.

All genes with less than 3 representative probes on the $1.0 \mathrm{R}$ tiling-array were excluded from further analysis. For the remaining 4,730 genes, the transcript abundance for each treatment-condition was calculated using the same median-polish methodology as used in the microarray analysis (PUBMedID: 18348734). The response of all genes $\left(G_{1-n}\right)$ in roots was assessed by normalizing according to the standard deviation $(\sigma)$ and declaring a gene as differentially expressed if $\left|G_{i} / \sigma\right|>=3$. This ensured that only the most differentially expressed genes (top 1.5\% in the root response) were considered to be regulated. This method was further employed to detect differential expression during root recovery, and again for the shoot response and recovery. Using this data, genes that are absent from the micro-array were classified into 1 of 9 response-and-recovery classes in a manner analogous to the classification of genes described by table 1. This method classified 477 out of the 4,730 tiling-array-specific genes as differentially expressed (Table 2); 171 genes were root specific, 242 were shoot specific, and 64 were systemically regulated. Details on the response and recovery for all 4,730 genes can be found in supplemental data (see Additional file 5).

\section{Analysis of functionally related gene loci}

Using GO-SLIM, we collected annotations and calculated $p$-values for all genes classified in both root and shoot datasets (1350 genes). The highest ranked term was, "cellular response to phosphate starvation" (Bonferroni adjusted $p$-value $=3.81 \times 10^{-13}$ ). Thirteen of the 21 genes annotated by this term were identified in genes expressed in both organs and they predominantly exhibited an IPR pattern. Several additional terms such as "galactolipid biosynthetic process" and"sugar:hydrogen symporter activity" were identified as significant. As expected, these terms described genes already known to be $\mathrm{P}_{\mathrm{i}}$ responsive. Therefore, we aimed to extend current knowledge by focusing on gene expression changes in the context of responseand-recovery and in the two separate organs.

\section{Expression patterns of known $P_{i}$ responsive gene loci in roots and shoots}

To facilitate comparison to prior studies, we were able to identify a total of 84 genes (AGI identifiers) that have been variously described in the literature and annotated by TAIR as being $\mathrm{P}_{\mathrm{i}}$-responsive (see Additional file 6). We clustered these 84 genes by their functional annotations (Figure 3-heatmap) and identified 8 partially overlapping functional clusters. Figure $3 \mathrm{a}-\mathrm{h}$ shows the gene expression patterns for these known $\mathrm{P}_{\mathrm{i}}$-responsive genes during both starvation and recovery in our root dataset. Generally, these 8 clusters grouped genes involved in transcription, plastid metabolism, response to wounding, $\mathrm{P}_{\mathrm{i}}$-transport, anthocyanin biosynthesis, and galacto- and glyco-lipid biosynthesis. Using a Bonferroni corrected $p$-value threshold of 0.001 we classified $30 \%$ of the 84 genes as IPR in roots. However, the majority (60\%) of the known loci did not significantly respond. This is perhaps not surprising because these genes were aggregated from the results of many studies, each employing a distinct protocol. Of the remaining 10\%, PEPCK2 displayed a persistent positive response to starvation whereas $A A T$ a persistent negative response. Two separate sets of genes each responded in roots in a latent manner: LPR (PAP1, CAT3, PHO1) and LNR (UGP, ORF02, ATPPC1, $L P R 1)$. Similar results were obtained when we performed the same analysis on gene expression levels in shoots. Comparison of the two organs showed that 14 genes (ATPAP1, ATPAP17, PHT1;4, PHT1;7, PHO1;H1, PHF1, PLDP2, MGD2, MGD3, SQD1, SQD2, SPX1, SPX2, and $S P X 3)$ shared IPR patterns among both. By contrast, the majority of the remaining IPR genes (At3g03530, DGD2, PAP6, PHT1;3, PHT1;1, PHT1;8, PHT1;9, PHT1;5) were non-responsive in shoots.

For the following functional analyses, gene lists were converted from lists of Affymetrix probe-ids to AGI identifiers. This step was necessary to maintain the accuracy of results, as the relationship between probe-ids and AGI identifiers is many-to-many, but probe-ids to transcript abundance and AGI-ids to functional-terms are one-to-one relationships.

In contrast to the 84 known $\mathrm{P}_{\mathrm{i}}$-responsive loci described above, we uncovered a more complex network of 1231 AGI gene identifiers that were also involved in root $\mathrm{P}_{\mathrm{i}}^{\text {starv }}$. Among these putative $\mathrm{P}_{\mathrm{i}}$-responsive genes we distinguished between those involved in the initial response from those in the latent response to $\mathrm{P}_{\mathrm{i}}^{\text {starv }}$. Upon further examination, we found that a small subset of 93 genes were neither aptly described as initial nor latent in their response patterns. Instead, these genes persisted in their initial expression and did not return to basal levels after a 3-day recovery; this was likely due to an insufficient recovery period for this group of genes. Thus, we investigated gene expression and function of these novel root $\mathrm{P}_{\mathrm{i}}$-responsive loci among 3 phases: 'INITIAL', 'PERSISTENT', and 'LATENT' (see Additional file 7).

\section{Three gene expression phases uncover functional responses to $P_{i}^{\text {starv }}$}

Considering both the response to and recovery from $\mathrm{P}_{\mathrm{i}}^{\text {starv }}$, we classified a gene's expression profile into one of three phases - initial, persistent, and latent. By definition, for a gene to be classified it had to be significantly differentially expressed in either the response to and/or recovery from 
Table 2 Responsive and recovering genes absent from the ATH1 micro-array

\begin{tabular}{|c|c|c|c|c|c|c|c|}
\hline \multicolumn{2}{|l|}{ Identifiers } & \multicolumn{3}{|l|}{ Root } & \multicolumn{3}{|l|}{ Shoot } \\
\hline AGI & Symbol & Res.* & Rec.* & Class & Res.* & Rec.* & Class \\
\hline \multicolumn{8}{|c|}{ Systemically Regulated } \\
\hline AT4G01060 & CPL3/ETC3 & 4.291 & -3.748 & IPR & 1.476 & -1.505 & IPR \\
\hline AT5G43300 & GDPD3 & 4.272 & -4.045 & IPR & 2.121 & -1.893 & IPR \\
\hline AT3G09922 & IPS1 & 5.971 & -4.591 & IPR & 6.572 & -5.800 & IPR \\
\hline AT4G19038 & LCR15 & 1.376 & -2.223 & LNR & 1.143 & -1.756 & LNR \\
\hline AT3G61172 & LCR8 & 0.412 & -1.981 & LNR & 0.518 & -1.667 & LNR \\
\hline AT2G41240 & BHLH1OO & -2.631 & 1.024 & PNR & -3.980 & 1.716 & INR \\
\hline AT3G07005 & LCR43 & -1.692 & 0.274 & PNR & 1.687 & -0.321 & PPR \\
\hline AT1G73607 & LCR65 & -2.178 & -0.235 & PNR & 1.417 & -1.490 & IPR \\
\hline AT3G56970 & ORG2 & -1.625 & 0.454 & PNR & -4.283 & 1.894 & INR \\
\hline AT3G61177 & LCR53 & 1.963 & -1.140 & PPR & -1.302 & 0.300 & PNR \\
\hline \multicolumn{8}{|c|}{ Root Specific } \\
\hline AT1G73165 & CLE1 & -1.977 & 1.924 & INR & -0.107 & -0.097 & BAR \\
\hline AT2G31081 & CLE4 & -2.012 & 2.875 & INR & 1.168 & -0.746 & BAR \\
\hline AT2G31082 & CLE7 & -1.952 & 2.312 & INR & 0.111 & 0.121 & BAR \\
\hline AT5G24920 & GDU5 & -2.877 & 3.590 & INR & 0.217 & 0.223 & BAR \\
\hline AT3G06985 & LCR44 & -1.885 & 2.264 & INR & 1.002 & -0.650 & BAR \\
\hline AT3G49570 & LSU3 & -2.308 & 1.684 & INR & 0.613 & 0.096 & BAR \\
\hline AT4G18197 & PUP7 & -1.770 & 1.755 & INR & 0.544 & -0.300 & BAR \\
\hline AT1G54760 & AGL85 & 1.941 & -2.146 & IPR & -0.136 & -0.280 & BAR \\
\hline AT5G06905 & CYP712A2 & 2.089 & -2.979 & IPR & -0.110 & -0.599 & BAR \\
\hline AT3G30725 & GDU6 & 3.627 & -5.125 & IPR & -0.030 & -0.020 & BAR \\
\hline AT2G32960 & PFA-DSP2 & 1.810 & -1.706 & IPR & 1.185 & -1.223 & BAR \\
\hline AT3G09400 & PLL3 & 2.523 & -2.929 & IPR & 0.978 & -0.054 & BAR \\
\hline AT4G27920 & RCAR4 & 2.259 & -2.132 & IPR & 0.734 & -0.431 & BAR \\
\hline AT1G53130 & $G R I$ & -0.375 & -1.756 & LNR & -0.056 & -0.117 & BAR \\
\hline AT3G61182 & LCR54 & 0.226 & -1.759 & LNR & -0.763 & -0.202 & BAR \\
\hline AT2G14365 & LCR84 & 0.519 & -1.936 & LNR & 0.756 & -0.101 & BAR \\
\hline AT4G10115 & SCRL2O & 0.348 & -2.985 & LNR & -0.297 & -0.485 & BAR \\
\hline AT4G29305 & LCR25 & -1.368 & 2.295 & LPR & 0.973 & -0.521 & BAR \\
\hline AT4G06746 & RAP2.9 & -1.617 & 3.125 & LPR & -0.404 & 0.512 & BAR \\
\hline AT4G23170 & EP1 & -2.487 & 0.662 & PNR & -0.033 & -0.134 & BAR \\
\hline AT4G09795 & LCR13 & -2.395 & 1.119 & PNR & -0.939 & 0.103 & BAR \\
\hline AT3G23167 & LCR39 & -1.694 & 0.502 & PNR & 0.556 & -1.297 & BAR \\
\hline AT4G18195 & PUP8 & -1.820 & 1.335 & PNR & -0.136 & -0.001 & BAR \\
\hline AT3G23715 & SCRL13 & -2.088 & 0.971 & PNR & 1.289 & 0.501 & BAR \\
\hline AT2G20825 & ULT2 & -1.640 & 0.337 & PNR & 0.339 & 0.139 & BAR \\
\hline AT5G45105 & ZIP8 & -2.392 & 0.846 & PNR & 0.284 & -1.101 & BAR \\
\hline AT4G22210 & LCR85 & 1.664 & 0.028 & PPR & 0.399 & -0.238 & BAR \\
\hline AT1G60815 & RALFL7 & 1.728 & -0.550 & PPR & 0.315 & 0.319 & BAR \\
\hline \multicolumn{8}{|c|}{ Shoot Specific } \\
\hline AT1G47510 & AT5PTASE11 & 0.182 & -0.184 & BAR & -1.362 & 1.610 & INR \\
\hline AT1G66145 & CLE18 & -0.570 & -0.135 & BAR & -1.422 & 1.680 & INR \\
\hline
\end{tabular}


Table 2 Responsive and recovering genes absent from the ATH1 micro-array (Continued)

\begin{tabular}{|c|c|c|c|c|c|c|c|}
\hline AT4G11485 & LCR11 & -0.969 & -1.131 & BAR & -1.695 & 1.849 & INR \\
\hline AT4G13890 & SHM5 & -0.177 & -0.165 & BAR & -1.534 & 1.421 & INR \\
\hline AT4G10767 & SCRL21 & -0.211 & -0.470 & BAR & 1.459 & -2.258 & IPR \\
\hline AT2G30432 & TCL1 & 0.062 & -0.924 & BAR & 1.680 & -1.893 & IPR \\
\hline AT1G06280 & $\angle B D 2$ & -0.667 & -0.194 & BAR & 0.729 & -1.385 & LNR \\
\hline AT4G29280 & LCR22 & -0.461 & -0.171 & BAR & 0.485 & -1.779 & LNR \\
\hline AT3G04430 & NACO49 & 1.550 & -0.809 & BAR & 0.731 & -1.440 & LNR \\
\hline AT1G23147 & RALFL3 & -0.093 & -0.201 & BAR & 1.262 & -2.229 & LNR \\
\hline AT5G45875 & SCRL27 & 0.864 & 0.235 & BAR & 0.754 & -1.712 & LNR \\
\hline AT4G31380 & $F L P 1$ & 0.549 & -0.073 & BAR & -0.234 & 1.555 & LPR \\
\hline AT4G29283 & LCR21 & -1.583 & -0.275 & BAR & 0.150 & 1.783 & LPR \\
\hline AT2G14935 & LCR40 & 0.461 & 0.290 & BAR & -0.469 & 1.423 & LPR \\
\hline AT2G12465 & LCR50 & 0.500 & -1.178 & BAR & -0.942 & 1.510 & LPR \\
\hline AT2G02147 & LCR73 & 0.599 & 1.466 & BAR & -0.563 & 1.383 & LPR \\
\hline AT2G04425 & LCR82 & 1.334 & 0.118 & BAR & -1.264 & 1.380 & LPR \\
\hline AT4G36950 & MAPKKK21 & 0.228 & -0.210 & BAR & -0.776 & 1.478 & LPR \\
\hline AT5G44430 & PDF1.2C & 0.682 & -1.123 & BAR & -0.528 & 1.747 & LPR \\
\hline AT2G05117 & $S C R L 9$ & -0.182 & 0.668 & BAR & -1.005 & 1.595 & LPR \\
\hline AT5G37415 & AGL105 & 0.684 & -0.214 & BAR & -1.931 & 0.608 & PNR \\
\hline AT2G45110 & EXPB4 & -0.018 & 0.286 & BAR & -1.495 & 0.106 & PNR \\
\hline AT1G07900 & $\angle B D 1$ & -0.174 & -0.103 & BAR & -1.834 & 0.837 & PNR \\
\hline AT3G43083 & LCR33 & -0.830 & 0.966 & BAR & -1.956 & 0.748 & PNR \\
\hline AT4G39917 & LCR45 & -0.321 & 0.020 & BAR & -1.897 & 0.452 & PNR \\
\hline AT5G14490 & NAC085 & 0.099 & -0.557 & BAR & -1.365 & 0.724 & PNR \\
\hline AT4G11653 & RALFL29 & -0.280 & -0.607 & BAR & -1.900 & 0.762 & PNR \\
\hline AT1G60625 & RALFL6 & -0.668 & 0.726 & BAR & -1.671 & 0.373 & PNR \\
\hline AT4G24230 & ACBP3 & 1.295 & -0.391 & BAR & 1.546 & -1.194 & PPR \\
\hline AT4G29273 & LCR23 & 0.128 & -0.851 & BAR & 1.352 & -0.802 & PPR \\
\hline AT2G19020 & RALFL10 & -1.217 & 0.276 & BAR & 1.745 & -1.112 & PPR \\
\hline AT2G34825 & RALFL2O & 0.240 & 0.456 & BAR & 1.375 & -0.603 & PPR \\
\hline AT5G08150 & SOB5 & 1.213 & -1.337 & BAR & 1.944 & -1.205 & PPR \\
\hline
\end{tabular}

This table presents 71 of the 477 tiling-array-specific genes identified as differentially expressed during the $P_{i}^{\text {starv }}$ response and/or recovery. These 71 were chosen only for the reason that they have been annotated with a gene symbol. The remaining 406 genes do not have gene symbols and are poorly annotated. See Additional file 5 for a complete list. *: Abbreviations for response (Res.) and recovery (Rec.).

$\mathrm{P}_{\mathrm{i}}^{\text {starv }}$. Thus, each phase may include genes that were either positively or negatively regulated. In this section we focus on genes that were root $\mathrm{P}_{\mathrm{i}}$-responders but not members of the group of 84 genes previously known to be $\mathrm{P}_{\mathrm{i}}$-responsive. Hence, all gene counts have been adjusted to exclude known $\mathrm{P}_{\mathrm{i}}$-responders. Genes that were responsive in the root's initial response phase consisted of 292 positively (IPR) and 112 negatively (INR) regulated genes whereas those persistently responsive included 45 positively (PPR) and 48 negatively (PNR) regulated genes. Finally, the root's latent response phase consisted of 423 positively (LPR) and 311 negatively (LNR) regulated genes.

To ascertain function, classified genes were annotated with GO-SLIM terms by which initial, persistent, and latent gene groups were annotated with 398, 146, and 665 functional terms, respectively. tMeV software [16,17] was employed to cluster functionally similar genes (Figure 4a (initial), 4e (persistent), 4i (latent)). Using functionalclusters we determined if gene members of any one functional-cluster displayed a stronger response than those of any other. To this end, we overlaid expression 


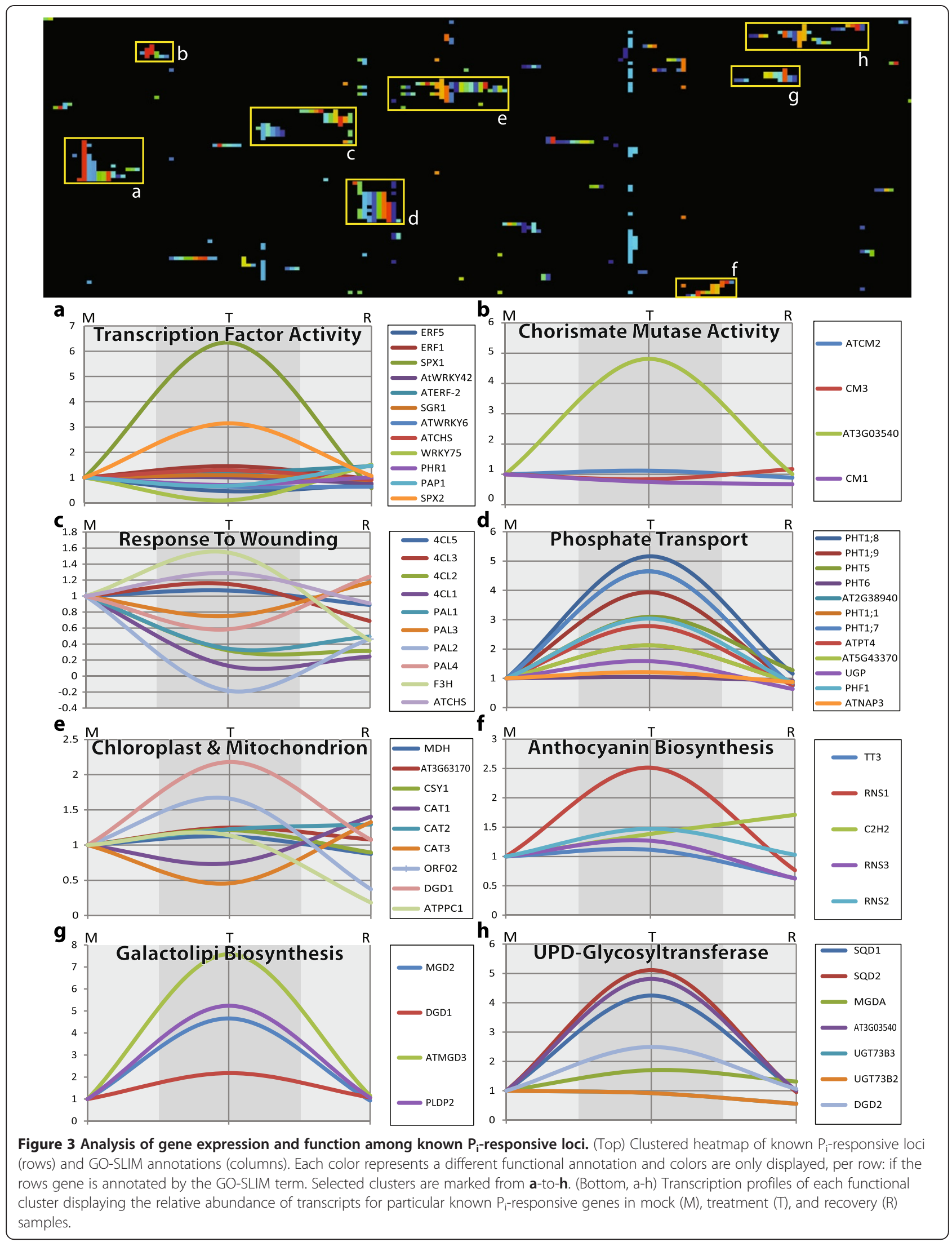




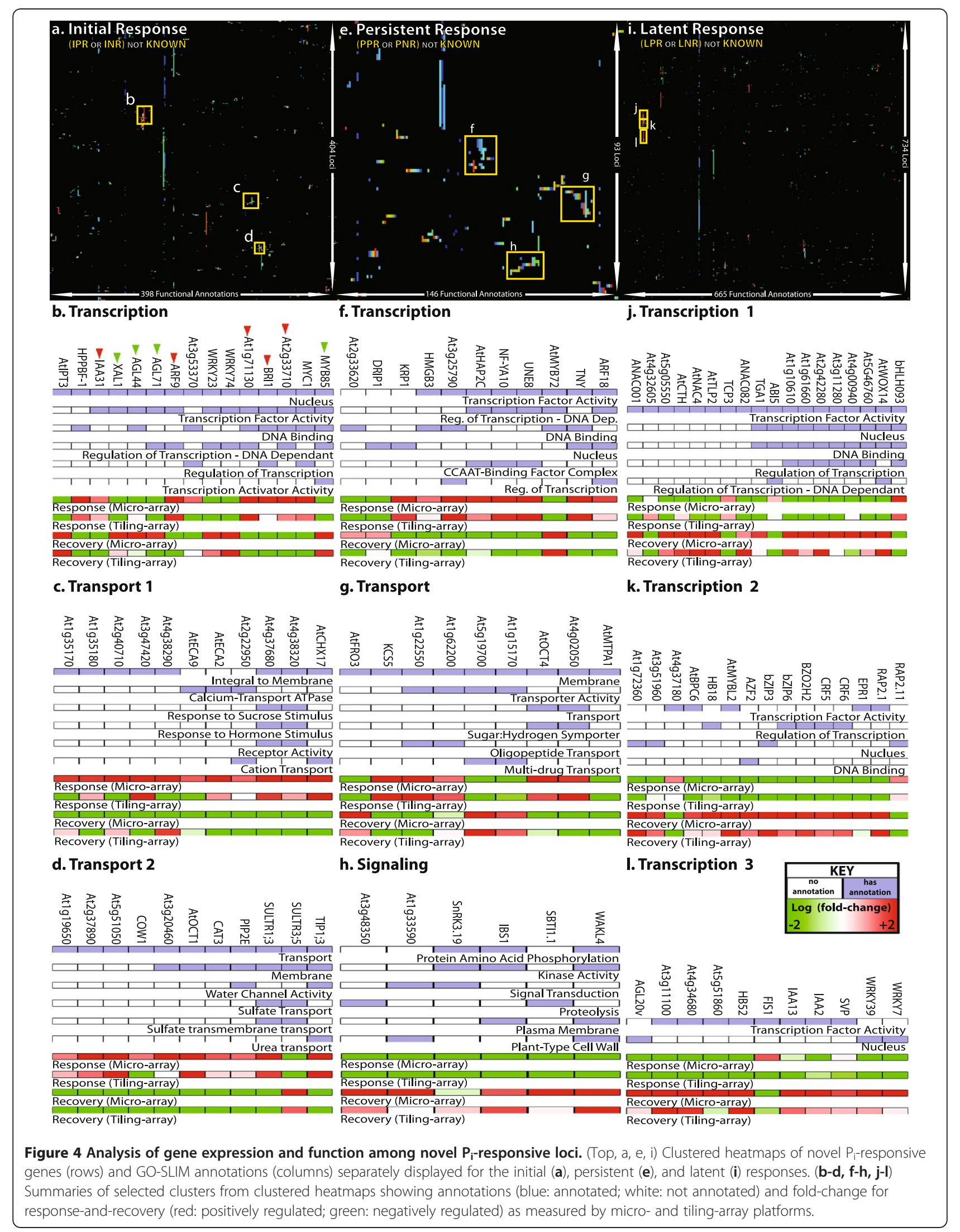


data with the heatmaps produced by $\mathrm{tMeV}$ (Figure 4). Figure 4 displays the results for each gene expression phase by highlighting results from the initial phase in the left column (Figure $4 \mathrm{~b}-\mathrm{d}$ ), the persistent phase in the middle column (Figure $4 \mathrm{f}-\mathrm{h}$ ) and the latent phase in the right column (Figure $4 \mathrm{j}-\mathrm{l}$ ). Three prominent functional clusters were highlighted for each phase: Genes were displayed across columns, functional annotations were shown as rows, and gene expression was indicated for both micro- and tiling-array root datasets.

Initially responsive gene clusters generally performed functions in "transcription regulation" (Figure 4b), "ionic transport" (Figure 4c), and "transmembrane transport" (Figure 4d). Among the transcription factor (TF) genes identified, AGL44, AGL71, XAL1(AGL12), MYB85, and WRKY23 were significantly down-regulated in roots (Figure 4b-green arrow). The agamous-like (AGL) TFs are known to be involved with root morphological processes [18], SOC1 is known to interact with both AGL44 and XAL1 [19], and MYB85 regulates lignin biosynthesis [20,21]. On the other hand, ARF9, BRI1, IAA31, At1g71130, and At2g33710 were up-regulated (Figure 4b-red arrow). Both At1g71130 and At2g33710 are members of the ERF/AP2 family with At1g71130 being involved in sugar:phosphate studies and At2g33710 in salt-stress. Thus, among others mentioned, At $2 g 33710$ encodes a TF candidate gene that deserves further studies with regards to its role in $\mathrm{P}_{\mathrm{i}}$-signaling. The second cluster of ionic transport genes were all up-regulated in roots in response to $\mathrm{P}_{\mathrm{i}}^{\text {starv }}$. Three gene members of this cluster (ECA9, ECA2, At2g22950) encode proteins involved in calcium ion transport. ECA9 is an auto-regulated $\mathrm{Ca}^{2+}$ efflux pump and the ECA2 ATPase catalyzes $\mathrm{Ca}^{2+}$ efflux. Similarly, $A T C H X 17$ is a sodium/proton anti-porter and the gene for this protein was expressed 6.4 fold higher in $\mathrm{P}_{\mathrm{i}}^{\text {starv }}$ than in the control, subsequently reducing its expression level by 5 fold during recovery. The third cluster included up-regulated genes encoding transporters. Most notably, genes for the sulfate and carnitine transporters, SULTR1;3 and OCT1, were up-regulated by 7 and 71.5 fold in $\mathrm{P}_{\mathrm{i}}^{\text {starv }}$, respectively. Indeed, OCT1 represented the most differentially expressed gene locus in this study.

Gene loci observed as persistently responsive were generally involved in "transcription regulation" (Figure 4f) and "ionic transport" (Figure 4g). These two functions were common to those seen among the initially responsive gene loci. However, a new function was also seen: "intracellular signaling" (Figure 4h). Of the TF genes (Figure 4f), $M Y B 72$ was the most differentially regulated locus in root (7 fold). This was followed by At3g25790, a putative MYB transcription factor (TF), which was up-regulated by 3.5 fold. The ethylene responsive TF gene, TNY (DREB A-4), exhibited a PPR expression pattern. It is involved in cytokinin biosynthesis [22], and cytokinin signaling is known to cross-talk with $\mathrm{P}_{\mathrm{i}}^{\text {starv }}$ signaling [23]. Additionally, the DRIP1 gene identified as a member of the PNR class, encodes an E3 ligase known to mediate ubiquitination of $T N Y$ 's family member DREB2A [24]. Finally, three CCAAT-binding TF genes were significantly up-regulated: NF-YA3 (HAP2C, 1.8 fold), NF-YA2 (HAP2B, 2.5 fold) and NF-YA10 (2.4 fold). The second persistently responsive gene cluster included genes coding for membraneassociated transport proteins (Figure 4g). MTPA1, a zincion efflux transporter, was the most differently expressed in root (down-regulated by 10.2 fold). The gene for the iron-reductase, FRO3, also displayed a persistent negative response of 2.8 fold. By contrast, two peptide transporter genes, At1g62200 and At1g22550, identified as members of the PPR class, have been implicated in zinc hyper-accumulation. And, the gene for another carnitine transporter, OCT4, displayed a PPR pattern with a 2.5 fold increase in transcript levels. In contrast to OCT1's IPR pattern (fold-change of 71.5), OCT4 did not return to basal expression levels during the recovery. The third persistently responsive gene cluster contained a mix of terms related to molecular signaling (Figure 4h). All genes within this cluster were negatively regulated and did not recover after 3 days in the replete medium. The most prominent members were WALK4 (3.4 fold down-regulated) and CIPK22 (3.3 fold down-regulated). The former encodes a member of the membrane-bound receptor-like kinase super family whereas CIPK22 encodes a protein known to associate with calcium-binding calcineurin B-like proteins [25]. Finally, At1g33590 which is involved in signal transduction and the karrikin response was persistently downregulated by 2.6 fold [26].

Among the latently responsive gene loci the most prominent expression patterns belonged to clusters implicated in transcription regulation. In total, we identified $48 \mathrm{TF}$ genes that were differentially expressed in roots during the recovery from, but not the response to starvation. This number exceeded the number of TF genes identified in the initial and persistent root response by 4 and 5.3 fold, respectively. Among proteins encoded by these $48 \mathrm{TF}$ genes, several TF families were prominently represented: (1) the major leucine zipper family including 5 bZIP, 5 $b H L H, 2 W R K Y$, and $2 H B$ TFs; (2) the ERF/AP2 family, with $5 \mathrm{TFs}$; (3) the zinc finger family, with $4 \mathrm{TFs}$; and (4), the NAC family, with 3 TFs. The remaining 22 TF genes were distributed among those encoding MYB, WUS, IAA, and other families. Of the first family of major leucine zippers, 14 were distributed across $b Z I P, b H L H, W R K Y$, and $H B$ sub-families. Members of the $b Z I P$ family are often involved in oxidative and pathogen defense responses and are commonly linked to ABA-related pathways [27,28]. In this group, genes for BZIP3, BZIP6, BZIP9, and BZIP24 were differentially regulated in root during recovery from, but not response to $\mathrm{P}_{\mathrm{i}}^{\text {starv }}$. The $b H L H$ gene family which 
is generally involved in plant development, circadian rhythm, and stress [29] included genes for BHLH093, MYC3, At1g10610, At1g61660, and At2g42280. The WRKY family members which mediate salicylic and jasmonic acid signaling are involved in defense against pathogens and/or herbivores [30]. We found WRKY7 and $W R K Y 39$ to latently respond to $\mathrm{P}_{\mathrm{i}}^{\text {starv }}$. Finally, we identified $H D$-ZIP18 and HD-ZIP52 as two latently responsive genes. The second family of ERF/AP2 TFs are involved in acclimation stress responsive to salicylic acid, jasmonic acid, cytokinin, and ethylene [31,32]. Here, we identified 2 cytokinin response factors including CRF5 and CRF6 whose genes were up-regulated during the recovery period. Genes for 3 ethylene response factors, RAP2.1, $R A P 2.11$, and HRE1, were found to express differentially during recovery. Members of the third major TF gene family encode zinc-fingers, of which we identified 4 positively regulated candidates, ZF2, AT4G00940, $A T C T H$, GATA3. The final pertinent TF genes identified were 3 members of the NAC family, NAC001, $N A C 080$, and NAC082, which were also up-regulated in a similar manner.

The functional diversity across the latently expressed TF gene families prompted us to attempt to identify common processes among them. To this end we employed the TAIR database that provides associations of peer-reviewed articles to genomic loci described within said articles. Collating articles associated to latently expressed TF genes, we used a simple textmining approach to group TF genes by previous research (see Additional file 8). We found $10 \mathrm{TF}$ genes (BZIP9, CRF6, MYBL2, NAC001, TGA1, ZF2, At1g61660, At2g03470, At4g32605, At4g37180) previously identified in studies on pathogen response and cell-cycle regulation during geminivirus infection [33]. A separate set of $7 \mathrm{TF}$ genes (MDB2, TLP2, ZF2, At1g08170, At2g03470, At3g11100, At4g37180) previously implicated in pollen germination and tube growth were latently regulated in roots [34]. Furthermore, 5 latently responsive TF genes (BHLH093, BZIP9, HB52, $R A P 2.1, T L P 2)$ were reported in a cold-acclimation study [35]. Additional smaller groups of TF genes were identified in publications investigating topics such as "primary and secondary metabolites" [36], "posttranscriptional regulation" [37], "sucrose" [38,39], and "basal resistance to pathogens" [40]. Many TF genes were found to be shared across several studies. Together, these results suggested novel roles for these TF genes in roots during recovery from $\mathrm{P}_{\mathrm{i}}^{\text {starv }}$. On the other hand, they also highlighted the importance to consider which $\mathrm{P}_{\mathrm{i}}$-responsive genes were $\mathrm{P}_{\mathrm{i}}$-specific or non-specific. In the following section, we addressed these issues for all differentially regulated genes by comparing our results with those published by the AtGenExpress initiative.
Interaction between $\mathrm{P}_{\mathrm{i}}$-responsive genes and those responsive to various AtGenExpress treatments

We defined interaction as a gene differentially regulated in at least 2 treatments. With differential regulation being determined by statistical significance $(\alpha=0.001$, using Bonferroni correction for multiplicity). To analyze possible interactions between the $\mathrm{P}_{\mathrm{i}}$ response and several hormonal, environmental, and nutritive treatments, we constructed a network using the following steps: (1) We analyzed datasets from various AtGenExpress treatments (with $\geq 2$ replicates) using the same methods and software as those for the analysis of our $P_{i}$ dataset (i.e. a Bonferroni-corrected $p$-value of $\leq 0.001$ versus respective control); (2) Genes differentially regulated in our root experiments were associated to AtGenExpress treatments for which they were differentially expressed; (3) We then weighted each gene-node by the number of treatments it was found to be differentially regulated and each treatment-node by the number of $\mathrm{P}_{\mathrm{i}}$-responsive genes found to be differentially regulated by that treatment. In this way, the network (Figure 5a) represented the degree to which genes interact with other treatments and which treatments elicit similar regulons to those initiated by $\mathrm{P}_{\mathrm{i}}^{\text {starv }}$ in the roots. Thus, we described: (1) genes found to be specific to $P_{i}^{\text {starv }}$ with no interaction among the treatments studied (Figure $5 \mathrm{~b}-\mathrm{P}_{\mathrm{i}}$ Specific); and (2) highly interactive genes providing evidence for co-regulation (Figure 5b).

\section{Gene loci specifically regulated during $P_{i}^{\text {starv }}$ only}

The following analysis was based on transcript abundance, therefore, Affymetrix probe-sets were used to represent genes and not AGI identifiers. By selecting a Bonferroni corrected p-value threshold of 0.001 , we sorted 1249 root $\mathrm{P}_{\mathrm{i}}$-responsive genes (Affymetrix probesets) into either $\mathrm{P}_{\mathrm{i}}$-specific or non-specific bins (Figure 5b). Although there were actually 1257 root $\mathrm{P}_{\mathrm{i}}$-responsive genes, 8 ambiguously mapped to AGI identifiers and were discarded from further analysis. Approximately $70 \%$ of the 1249 genes were $\mathrm{P}_{\mathrm{i}}^{\text {starv }}$ specific in roots, i.e. 869 genes were either initially (24\%), persistently (5\%), or latently (41\%) responsive to $\mathrm{P}_{\mathrm{i}}^{\text {starv }}$ and did not interact with those affected in other AtGenExpress treatments.

The $\mathrm{P}_{\mathrm{i}}$-specific genes included those already known to be $\mathrm{P}_{\mathrm{i}}$-responsive and those that were novel factors of $\mathrm{P}_{\mathrm{i}}^{\text {starv }}$ response identified here. At a corrected $p$-value $\leq 0.001$, 28 known $\mathrm{P}_{\mathrm{i}}$-responsive genes tended to be exclusively regulated by $\mathrm{P}_{\mathrm{i}}^{\text {starv }}$. Because this type of Boolean analysis did not distinguish between genes in terms of their specificity, we ascertained the minimum threshold ( $p$-value) required to reclassify a $\mathrm{P}_{\mathrm{i}}$-specific gene as being nonspecific (Figure $5 \mathrm{~d}$ ). The higher the $p$-value required, the greater the gene's specificity to $\mathrm{P}_{\mathrm{i}}^{\text {starv }}$. Therefore, by 


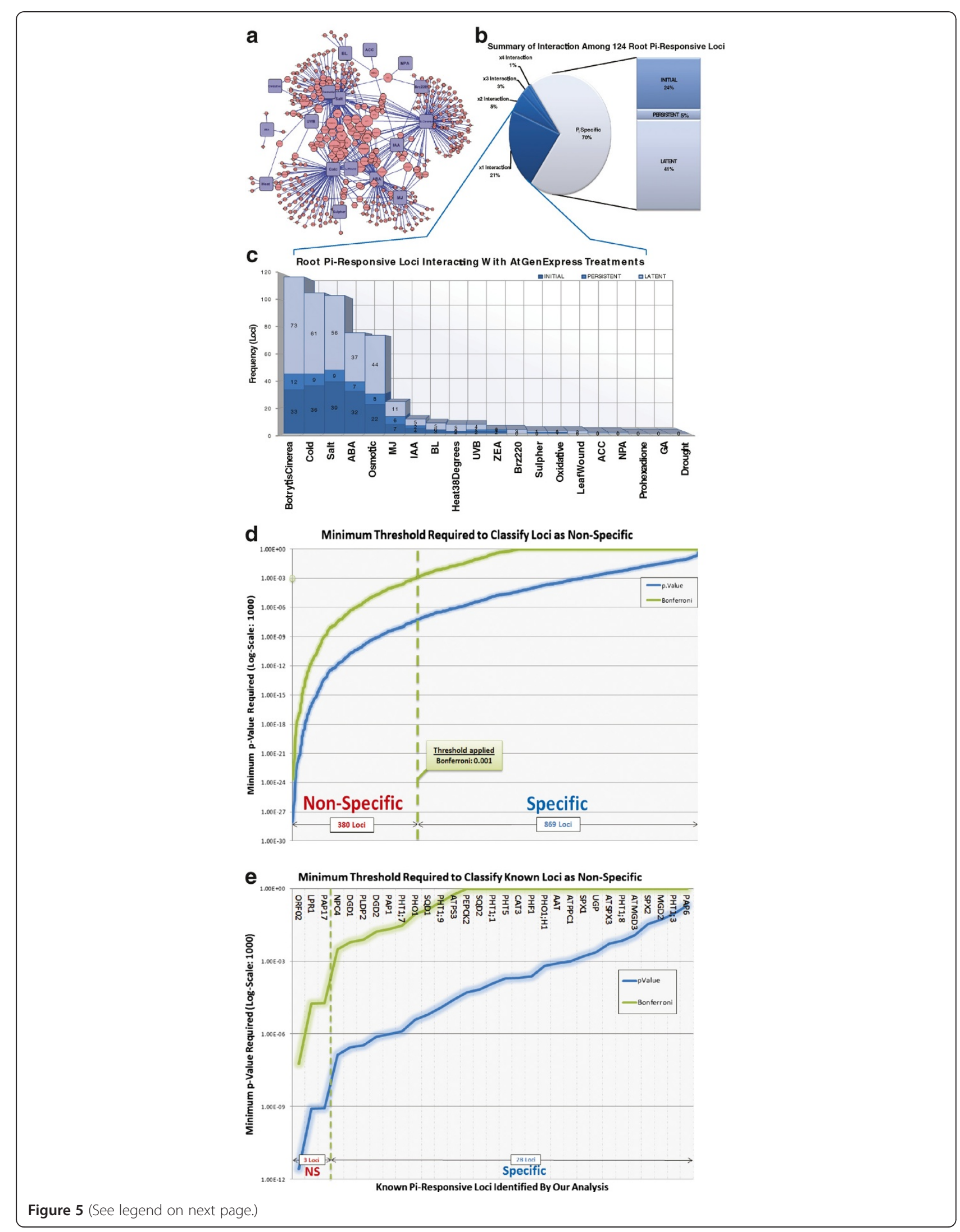


(See figure on previous page.)

Figure $\mathbf{5}$ Comparative analysis between $\mathbf{P}_{\mathbf{i}}^{\text {starv }}$ data and AtGenExpress. Subfigure (a) depicts a network of interactions between several types of treatment (blue squares) and genomic loci (other nodes) represented by probes on the ATH1 micro-array. Edges/lines are drawn between treatments and loci if the locus is differentially regulated in the treatment as compared to its control (see Additional file 9). (b) A pie chart summarizing the degree to which loci were found to interact with AtGenExpress treatments. Seventy percent of $\mathrm{P}_{\mathrm{i}}$-responsive loci are found to interact with nothing else, whereas 21\% interact with 1 other AtGenExpress treatment and 1\% interact with 4 AtGenExpress treatments. (c) Stacked histogram breaking down the degree of interactivity in terms of locus counts (y-axis) between various AtGenExpress treatments (x-axis). From bottom-to-top the stacked bars indicate the contributions made by the initial, persistent, and latent responses. (d) A plot describing the minimum threshold required ( $y$-axis; $p$-value: blue; corrected: green) in order to detect a locus ( $x$-axis; ranked by $y$-axis) as being differentially regulated in at least 1 AtGenExpress treatment. A dotted green line indicates the default threshold used by our analysis that results in 380 loci being detected in at least 1 AtGenExpress treatment and are therefore classified as non-specific. (c) A plot identical to (d), except only a subset of loci (x-axis) that are known to be $\mathrm{P}_{\mathrm{i}}$-responsive are displayed.

ranking each gene according to this minimum $p$-value threshold, we could compare their relative interaction. For instance, among the known set of genes, we found $P H O 1$, PHO1;H1, DGD1, and PHF1 to be specifically regulated in response to $\mathrm{P}_{\mathrm{i}}^{\text {starv }}$ (Figure $5 \mathrm{e}$ ). We also observed that PAP6, PHT1;3, and MGD2 ranked higher than any other known $\mathrm{P}_{\mathrm{i}}$-responsive genes and were therefore relatively more specific to $\mathrm{P}_{\mathrm{i}}^{\text {starv }}$ than to any other treatments tested. Indeed, PAP6 displayed the most specificity to $\mathrm{P}_{\mathrm{i}}^{\text {starv }}$, requiring a notably relaxed threshold ( $p$-value $\leq 0.2)$ in order to be classified as non-specific. Given the tendency of known $\mathrm{P}_{\mathrm{i}}$-responsive genes to include multiple members of the same family (such as ion-transporters), we were able to ascertain the relative specificity of the family members (Figure 5e): (1) Among the PHT1 $\mathrm{P}_{\mathrm{i}}$-transporter family members, genes for PHT1;3 (42 ${ }^{\text {nd }}$ most $\mathrm{P}_{\mathrm{i}}$-specific), PHT1;8 (226 $6^{\text {th }}$ most $\mathrm{P}_{\mathrm{i}}$-specific), PHT1;1 (503 $\left.{ }^{\text {rd }}\right)$, PHT1;9 $\left(637^{\text {th }}\right)$, and PHT1;7 $\left(726^{\text {th }}\right)$ were all $\mathrm{P}_{\mathrm{i}}^{\text {starv }}$ specific; (2) Among the lipid processing families, both MGD2 and MGD3 were highly ranked at $82^{\text {nd }}$ and $189^{\text {th }}$, respectively, whereas, DGD2 and DGD1 were less specific with ranks of 760 and 811, respectively; (3) Three members of the SPX gene family were highly ranked at 330 (SPX1), 246 (SPX3), and 114 (SPX2); finally, (4) PHO1, a well-studied gene, was less specific (ranked $684^{\text {th }}$ ) than its close homolog, PHO1;H1 (ranked 394 ${ }^{\text {th }}$ ).

After ranking all $\mathrm{P}_{\mathrm{i}}$-responsive genes in our study (see Additional file 10), we found that several hundred $\mathrm{P}_{\mathrm{i}^{-}}$ responsive genes identified here were more specific to $\mathrm{P}_{\mathrm{i}}^{\text {starv }}$ than many genes previously reported as being $\mathrm{P}_{\mathrm{i}^{-}}$ responsive. For example, the top 100 most $\mathrm{P}_{\mathrm{i}}$-specific genes included only 3 members previously described as being $\mathrm{P}_{\mathrm{i}}$-responsive. These 3 were PAP6 ranked $7^{\text {th }}$, PHT1;3 ranked $42^{\text {nd }}$, and $M G D 2$ ranked $82^{\text {nd }}$. The remaining 97 genes responded to starvation in either an initial (49 genes), persistent (10 genes) or latent (38 genes) manner. The most $\mathrm{P}_{\mathrm{i}}$-specific and initially responsive genes included At4g19770 (encoding a putative chitinase, responding at 3.5 fold and recovering at 4.3 fold) ranked $1^{\text {st }}$, At4g25160 (encoding a receptor-like cytoplasmic kinase with similarity to universal stress response protein of bacteria, responding at 7.5 fold and recovering at 16.5 fold) ranked $3^{\text {rd }}$ and At1g04700 (encoding a tyrosine kinase, responding at 1.8 fold and recovering at 2.2 fold) ranked $5^{\text {th }}$. Genes that persistently responded to starvation during recovery include MTPA1 (encoding a zinc transporter, responding at 10.2 fold) ranked $2^{\text {nd }}$, At3g53770 (encoding a LEA3 family member, responding negatively at 3.8 fold) ranked $6^{\text {th }}$, and MYB72 (encoding a TF mediating systemic resistance, responding negatively at 7.3 fold) ranked $8^{\text {th }}$. Finally, the top most specific latently responsive genes included At1g62090 (encoding a pseudogene-protein kinase, recovering negatively at 1.6 fold) ranked $10^{\text {th }}$, At5g66220 (encoding a chalcone-flavanone isomerase, recovering negatively at 1.6 fold) ranked $12^{\text {th }}$, and At3g26130 (encoding a cellulase, recovering at 1.8 fold) ranked $13^{\text {th }}$.

\section{$P_{i}$-responsive genes co-regulated in multiple AtGenExpress treatments}

Approximately $70 \%$ of the $1249 \mathrm{P}_{\mathrm{i}}$-responsive genes in roots identified here were $\mathrm{P}_{\mathrm{i}}$-specific at a $p$-value $\leq$ 0.001 . There was no detectable response of these genes among any AtGenExpress treatments covering stimuli ranging from hormonal and nutritional to environmental. The remaining $30 \%$ of genes (380) were not considered $\mathrm{P}_{\mathrm{i}}$-specific because they differentially responded with up to 4 additional treatments found in AtGenExpress. We exploited this behavior in an attempt to elucidate: (1) treatments displaying the most similarity to $\mathrm{P}_{\mathrm{i}}^{\text {starv }}$ in terms of differentially regulated genes; (2) gene interaction and regulation by hormonal treatments; and (3) cohorts of co-regulated genes.

To determine which treatments were most similar to $\mathrm{P}_{\mathrm{i}}^{\text {starv }}$, we considered only those genes significantly regulated. We counted the frequency of genes differentially regulated in both $\mathrm{P}_{\mathrm{i}}^{\text {starv }}$ and each AtGenExpress treatment. We then weighted treatment-nodes by this frequency and ranked them (histogram, Figure 5c). Our results showed that Botrytis cineria infection (118 common genes) followed by cold (106), salt (104), and osmotic (74) stress 
treatments were most similar to $\mathrm{P}_{\mathrm{i}}^{\text {starv }}$. Furthermore, most genes interacting with these treatments were latently responsive in our experiments, and were mostly associated to one other non- $\mathrm{P}_{\mathrm{i}}$-related treatment. We found that the maximum degree of interaction displayed by any $\mathrm{P}_{\mathrm{i}}$-responsive gene was 4 AtGenExpress treatments (Figure 5b, Figure 6a-d).

Among the hormone treatments tested (ABA, ACC, $\mathrm{BL}, \mathrm{GA}$, IAA, MJ, and ZEA) ABA treatment with 76 common genes displayed the most interaction with $\mathrm{P}_{\mathrm{i}}^{\text {starv }}$. After which, the frequency declined sharply to $\mathrm{MJ}$ treatment (24 common genes), IAA treatment (11), BL treatment (8), ZEA treatment (3), ACC treatment (1) and GA treatment (0). Close inspection of those $\mathrm{P}_{\mathrm{i}}$-responsive genes associated with ABA treatment uncovered many genes related to cold, salt, and osmotic treatments (Figure 6a-d). Of the 10 genes interacting with ABA, cold, salt, and osmotic treatments, only AZF2, CYP706A2, SPS2F, and TRI have been annotated in public databases. Not surprisingly, salt and osmotic treatments shared several responsive genes; these genes were also $\mathrm{P}_{\mathrm{i}}$-responsive and included $A A P 1, M Y B 74$, and SS2.

Overall, inspection of the interaction-network uncovered clusters of co-regulated genes. The most central cluster of genes consisted of those associated with treatments most similar to $\mathrm{P}_{\mathrm{i}}^{\text {starv }}$. These genes included $A Z F 2$ (zinc finger protein, known to be regulated by ABA, salt, and desiccation), SP2F (putative sucrose-phosphate synthase activity), TRI (tropinone reductase), At1g52560 (HSP20like), At1g62570 (Flavin-Monooxygenase family implicated in multiple-stress studies), At3g01260 (Galactosemutarotase family), and At5g35735 (Galactose-mutarotase family). These clusters of interacting genes suggest co-regulatory mechanisms and may therefore lead to the discovery and/or elucidation of possible novel $\mathrm{P}_{\mathrm{i}^{-}}$ responsive network.

\section{Discussion}

High-throughput technologies recently applied to studying $\mathrm{P}_{\mathrm{i}}^{\text {starv }}$ in Arabidopsis have contributed to the overall understanding of how plant molecular systems react to $\mathrm{P}_{\mathrm{i}}$-limiting stress [9-14]. However, comparing results from these studies is problematic due to different experimental designs. For example, Misson et al. (2005) [9] focused on leaf and root tissues, whereas Muller et al. (2007) [11] examined shoot tissues; Muller et al. (2007) additionally studied those genes that interact with pathways evoked during sucrose limiting stress. These studies shared the overall strategy to investigate a plant's initial responses to $\mathrm{P}_{\mathrm{i}}^{\text {starv }}$. Only one high-throughput study has thus far characterized the molecular response during recovery from $\mathrm{P}_{\mathrm{i}}^{\text {starv }}$ [10]. This work demonstrated that a subset of genes found to respond to $\mathrm{P}_{\mathrm{i}}^{\text {starv }}$ by prior research could also recover and thus identified high-confidence candidates sensitive to $\mathrm{P}_{\mathrm{i}}$-flux. Together, these four studies have significantly increased our current understanding of $\mathrm{P}_{\mathrm{i}}^{\text {starv }}$ on a genome-wide scale. This report furthers the knowledge garnered by those four reports described above by combining their experimental designs under a single framework. Hence, the data described here offers insights into areas previously unreported, such as the transition between the initial response and the latent recovery phases, the detection of organ-specific differences in gene regulation and the combination of both to define the systemic plant response.

Thirty-six organ- and response-specific arrays were analyzed with the initial aims of generating a reference dataset for molecular responses to $\mathrm{P}_{\mathrm{i}}^{\text {starv }}$ to provide additional insights for those responses and to identify new $\mathrm{P}_{\mathrm{i}}$-responsive candidate genes. To manage this dataset, a classification scheme was designed to broadly categorize novel response-and-recovery gene expression patterns. Using this scheme a unique and comparably large molecular response was identified in roots relative to shoots. We analyzed the interaction of $\mathrm{P}_{\mathrm{i}}$-responsive genes with several hormonal, environmental, and nutritive treatments. This exercise defined non-specific $\mathrm{P}_{\mathrm{i}}^{\text {starv }}$ genes differentially regulated across multiple stimuli; in particular, stimuli such as cold, osmotic, and salt stress. Furthermore, the hormone ABA appeared to regulate substantially more $\mathrm{P}_{\mathrm{i}}$-sensitive genes than other hormone treatments. This supports the premise that of the hormone regulators ABA is likely a key player during $\mathrm{P}_{\mathrm{i}^{-}}$ flux. Significantly, the majority of genes known to respond to $\mathrm{P}_{\mathrm{i}}^{\text {starv }}$ were observed to be regulated by several different treatments. Thus, this known gene-set that includes many well described $\mathrm{P}_{\mathrm{i}}^{\text {starv }}$-sensitive genes such as PHO1 is indeed not $\mathrm{P}_{\mathrm{i}}^{\text {starv }}$-specific. To place this into context we note that many genes not previously identified as $\mathrm{P}_{\mathrm{i}}$-responsive, but identified as responsive here exhibit a lesser degree of cross-talk and hence occupy roles that are relatively more $\mathrm{P}_{\mathrm{i}}^{\text {starv }}$-specific. This insight provides opportunity for both generating and addressing additional questions regarding the regulation of molecular networks during nutrient stress. Given the nature of genome-wide technologies employed here much depends on the wealth of knowledge and annotations generated by prior researchers studying several genes using non-high-throughput methods. Therefore, a thorough literature and database survey was conducted for both those genes known to respond to $\mathrm{P}_{\mathrm{i}}^{\text {starv }}$ and those additional genes observed during the course of this study. Thus, we were able to report on all results in the context of novel findings by examination of candidate genes and their corresponding gene expression patterns during the response and recovery. 
Figure 6 Cross-talk between $\mathrm{P}_{\mathrm{i}}^{\text {starv }}$, ABA treatment and cold, salt, and osmotic stress. Subfigures (a) through (d) display highlighted portions of Figure $5 \mathrm{a}$. Pi-responsive loci are highlighted (yellow) if they have additionally been found to be regulated by ABA treatment (a), cold stress (b) salt stress (c), and/or osmotic stress (d). The degree of overlap between highlighted regions is high indicating a large degree of cross-talk between treatments.

\section{Comparisons among different studies reveal the need to establish a reference dataset}

Although previous experiments by various groups have, in aggregate, reported a total of $84 \mathrm{P}_{\mathrm{i}}$-responsive genes, our work here has observed $40 \%$ of these genes being responsive to starvation and recovery treatment. As this appeared to be a small proportion we addressed this issue by analyzing the benchmark set by previous genome-wide experiments: Misson et al. (2005) [9], Morcuende et al. (2006) [10], Muller et al. (2007) [11], and Nilsson et al. (2010) [12] each identified 14\%, 33\%, $3 \%$, and $8 \%$ of the 84 significantly responsive genes, respectively. Therefore, due to the lack of overlapping results, it appears that the core set of known $\mathrm{P}_{\mathrm{i}}$-responsive genes is highly variable and most likely dependent on the experimental approach. This between-study variation highlights the need to standardize experimental designs and to ascertain the cause behind the regulation of core $\mathrm{P}_{\mathrm{i}}$-responsive genes.

Among 33 of the known $84 \mathrm{P}_{\mathrm{i}}$-responsive genes identified, the majority (75\%) were found to be initially responsive and their expression returned to basal levels during recovery. Only $24 \%$ of the genes were latently responsive and the remaining $1 \%$ was persistently responsive. We propose that the bias towards the initial response is due to prior research almost exclusively focusing on the starvation response without considering recovery. Thus, known $\mathrm{P}_{\mathrm{i}}$-responsive genes tend to be initially responsive. Only a few studies have examined recovery from starvation which is reflected by the lower proportion of known genes identified as being latently expressed.

\section{Expression profiles of $\mathrm{P}_{\mathrm{i}}$-starvation responsive genes absent from the ATH1 micro-array}

Even though the ATH1 micro-array lacks genome-wide coverage it has been widely used for transcriptome studies. Whereas the 1.0R tiling-array is not comprehensive it certainly interrogates more of the Arabidopsis genome than ATH1 and therefore has a distinct advantage. However, the public literature surrounding array-based studies is dominantly micro-array based. Analyses and methods using the micro-array architecture are better described and the genes represented by the ATH1 chip are, in general, better annotated. Therefore, given the goal of this study to better characterize the molecular 
response and recovery to $\mathrm{P}_{\mathrm{i}}^{\text {starv }}$, the micro-array platform was chosen as the primary means to analyze gene expression. Nevertheless, our acquisition of tiling-array data in parallel serves to both corroborate micro-array results as well as to investigate the response and recovery of those genetic elements not represented by ATH1 probes. We have determined the response and recovery profiles for all 5,044 nuclear protein coding genes absent from the ATH1 micro-array (see Additional file 5) and detected 477 genes that may play a role during and post $\mathrm{P}_{\mathrm{i}}^{\text {starv }}$ in roots and shoots (Table 2). Among those 477 genes we identified IPS1 (now known as non-protein coding), GDPD3 (a membrane-remodeling factor) and CPL3 (a MYB TF), for which we describe their biology and response to $\mathrm{P}_{\mathrm{i}}^{\text {starv }}$ below.

IPS1 is a $\mathrm{P}_{\mathrm{i}}^{\text {starv }}$-inducible non-coding RNA whose transcript level is regulated by a myb transcription factor, PHR1 [41]. By a mechanism known as target-mimicry, IPS1 is resistant against the activity of RISC-loaded miRNA399 due to its partial sequence complementarity to the mature miR399. This property enables IPS1 the ability to quench the miR399 signal without being cleaved by the latter [42]. RT-PCR showed that the IPS1 transcript level was inversely correlated to $\mathrm{P}_{\mathrm{i}}$ availability in hydroponic media (see Additional file 4). This was also shown by tiling-array analysis of roots and shoots for which the responses $\left(\log _{2}\left(\mathrm{P}_{\mathrm{i}}^{\text {starv }} / \mathrm{P}_{\mathrm{i}}^{\text {mock }}\right)\right)$ were 6 and 6.5 , respectively. The IPS1 expression profile was the most differentially regulated profile among the 5,044 tiling-array-specific genes examined. Given the established role of IPS1 during $\mathrm{P}_{\mathrm{i}}^{\text {starv }}$, this gene represents an excellent positive control for the remaining 476 genes identified by the tiling-array platform alone.

Unlike IPS1, the glycerophosphodiester phosphodiesterase (GDPD) gene family member, GDPD3, was not implicated in $\mathrm{P}_{\mathrm{i}}$ homeostasis until 2011 [43]. Our tiling-array data corroborated this result as GDPD3 (At5G43300) exhibited a 19 fold increase in signal intensity during the $\mathrm{P}_{\mathrm{i}}^{\text {starv }}$ response in roots. The function of the GDPD family has been implicated in $\mathrm{P}_{\mathrm{i}}$-recycling through a membrane remodeling process that is sensitive to $\mathrm{P}_{\mathrm{i}}$-flux. Together with the vacuole, phospholipid bilayers are a major reservoir of internal cellular $\mathrm{P}_{\mathrm{i}}$. Membrane remodeling is a physiological response of plant cells to supply $\mathrm{P}_{\mathrm{i}}$ on demand. This method of $\mathrm{P}_{\mathrm{i}^{-}}$ recycling replaces phospholipids in internal cellular membranes with alternate forms such as galacto- and sulfo-lipids $[44,45]$. GDPD hydrolyzes glycerolphosphodiesters originating from phospholipids and produces a glycerol-3-phosphate (G-3-P) and a corresponding alcohol. The G-3-P byproduct is further degraded by acid phosphatases resulting in $\mathrm{P}_{\mathrm{i}}$ accumulation [43]. This remodeling mechanism is one example of a plant-wide response to $\mathrm{P}_{\mathrm{i}}$-limitation at a micro-scale, in addition to responses at the macro scale, e.g. by remodeling root architecture.

Plasticity of root architecture is related to the availability of soil nutrients under fluctuating environmental conditions. Under $\mathrm{P}_{\mathrm{i}}$-limiting conditions, root architecture changes by inhibiting primary root growth and promoting increased density of both lateral roots and root hairs [46]. Cell fate of epidermal trichoblast and atrichoblast is specified by several negative cell and non-cell autonomous regulators GL2, CPC, TRY, and ETCs [46]. On the other hand, CAPRICE LIKE MYB3 (CPL3) has been characterized as a positive regulator for root hair patterning [47]. Since CPL3 is not represented by ATH1 probes and hence unlikely to be described in previous studies of $P_{i}$ starvation, we were interested to gauge this gene's response and recovery from our tiling-array data. Indeed, CPL3 was initially up-regulated by 19.6 fold in roots and returned to basal levels during recovery (IPR). Whilst less remarkable the shoot response also displayed an IPR pattern of gene expression exhibiting an initial fold-change of 2.8. Therefore, the $\mathrm{P}_{\mathrm{i}}^{\text {starv }}$ response may involve CPL3 to govern root hair patterning. Our identification of CPL3, GDPD3, IPS1, and the other 474 genes as being $P_{i}^{\text {starv }}$-responsive exemplifies the utility of tiling-arrays in $\mathrm{P}_{\mathrm{i}}^{\text {starv }}$ studies with regards to discovering new candidates for future research.

\section{A novel root response suggests roles for energy metabolism and ionic transport}

Previous $\mathrm{P}_{\mathrm{i}}^{\text {starv }}$ research has not yet addressed root responses from the perspective of genome-wide studies. Whereas whole seedling experiments have undoubtedly captured a part of the root's responses, the results are likely skewed towards shoot responses as we have found that in 2 week old seedlings the average root to shoot RNA-abundance ratio is 1:9 (data not shown). Here, we found that the number of responsive genes in roots was 6.9 fold higher than those in shoots. Additionally, the distribution of genes in terms of fold-change in their response-and-recovery highlights greater responses to $\mathrm{P}_{\mathrm{i}}^{\text {starv }}$ in roots than shoots (Figure 1). Furthermore, only $7 \%$ of $\mathrm{P}_{\mathrm{i}}$-responsive genes in roots were significantly altered in shoots. These 3 observations emphasize the importance of a global analysis of the root-specific response which hitherto has been neglected. To better understand the root response, we divided all root responsive genes into 1 of 3 categories (initial, persistent, or latent), and selected 3 prominent (in terms of foldchange) clusters of functionally related genes per category. Among genes in the initially responsive category, the most prominent clusters were involved in ion and trans-membrane transport, specifically calcium and sodium ion transport (Figure 4c,d). Whereas, the third prominent cluster grouped genes functioning in transcription regulation (Figure $4 \mathrm{~b}$ ). 
We found lipid metabolism to play a role in the initial and persistent response. OCT1 was co-identified with several membrane transporters in the initial response. OCT1 exhibited the most fold-change of any gene observed before returning to basal levels during recovery. Similarly, OCT4 was identified in the persistent category and while it did not recover it also did not display as dramatic a fold-change as OCT1. OCT1 and OCT4 encode carnitine transporters involved in mitochondrial fatty acid metabolism. Arabidopsis mutants deficient in OCT1 and transgenic plants overexpressing 35 S::OCT1 have been shown to promote and suppress lateral root hair development, respectively [48]. Paradoxically, OCT1 is up-regulated 71-fold during $\mathrm{P}_{\mathrm{i}}^{\text {starv }}$, but lateral root hair development is positively regulated during $\mathrm{P}_{\mathrm{i}}$-limitation. Thus, OCT1 appears to be uncoupled from root hair development during $\mathrm{P}_{\mathrm{i}}^{\text {starv }}$ and may hypothetically play a role in $\mathrm{P}_{\mathrm{i}}^{\text {starv }}$-induced lipid/energy metabolism.

\section{The root up-regulates transcription factors as the system tends toward recovery}

Regulation of $A G L$ expression occurred during the initial response but regulation of the $N F-Y A$ family members persisted after the recovery period, although the reason for this difference is presently unknown. Nevertheless, our results provide a shortlist of additional TF candidates for future research. Considering both the number of additional TF genes displaying initial and persistent responses, it is likely that the $\mathrm{P}_{\mathrm{i}}^{\text {starv }}$ response is regulated by more than just the two TFs (PHR1, PHL1) identified to date $[13,49]$ as previously corroborated $[12,50]$. Indeed, we observed a marked increase in the number of differently regulated TF genes (48 TFs) during the latent response, which increased by 4 and 5.3 fold from the number of TF genes observed during the initial and persistent responses, respectively. These results suggest that significant regulatory changes occurred latently during the period of recovery from $\mathrm{P}_{\mathrm{i}}^{\text {starv }}$. Using a text-mining approach we have uncovered some $\mathrm{P}_{\mathrm{i}}$-responsive TF genes to be involved in viral infection, cold acclimation and even pollen tube growth (PTG). Interaction of $\mathrm{P}_{\mathrm{i}}$-responsive TF genes with genes involved in viral defense and cold acclimation can be explained if a general stress response underlies all three cases. In addition, root hair extension is promoted during $\mathrm{P}_{\mathrm{i}}^{\text {starv }}$ and is known to share many common features with pollen tube growth (PTG).

\section{Expression of IPT3, ARF9, and MYB85 may alter root- morphology during $\mathrm{P}_{\mathrm{i}}^{\text {starv }}$}

During $\mathrm{P}_{\mathrm{i}}^{\text {starv }}$ the root architecture is significantly altered through both negative and positive regulation of primary and lateral root (LR) development. Root development processes are known to be down-regulated by cytokinin
(CK) at high concentrations [51]. Therefore, $\mathrm{P}_{\mathrm{i}}^{\text {starv }}$ may be expected to reduce endogenous CK concentrations to release LR developmental pathways. Although CK concentrations were not directly measured in our experiments, we found a significant down regulation of IPT3 in roots suggesting an additional $P_{i}^{\text {starv }}$-specific role for this gene in root $\mathrm{CK}$ biosynthesis.

Our results show an increased expression of ARF9 in root tissues, although this gene has not yet been reported to play a role in root architecture nor in the $\mathrm{P}_{\mathrm{i}}^{\text {starv }}$ response. However, ARF9 is known to be up-regulated by high auxin concentrations similarly to its family members $A R F 7$ and ARF19, which promote LR formation in initiating cells accumulating auxin [52]. This shows that ARF9 does have a role in $\mathrm{P}_{\mathrm{i}}^{\text {starv }}$ and suggests that the role may be in morphological changes of root architecture.

Development of LR first entails the removal of structural scaffolds within cell walls, a process critical for cell expansion and proper root hair development. This process requires both the down-regulation of positive regulators (MYB69 and MYB85) as well as an up-regulation of negative regulators. We found that $M Y B 69$ and canonical upstream regulatory genes (SIZ1, SND1, NST1, and VND6) were all basally regulated during $\mathrm{P}_{\mathrm{i}}^{\text {starv }}$ in roots. Yet, expression of MYB85 (required for proper lignin deposition) was significantly reduced. This selective down-regulation of MYB85 suggests attenuation of lignin deposition, resulting in a favorable environment for initiation of root hairs under $\mathrm{P}_{\mathrm{i}}^{\text {starv }}$.

\section{Cross-talk among $\mathrm{P}_{\mathrm{i}}^{\text {starv }}$ candidates uncovers interaction with plant hormones}

To observe possible cross-talk between $\mathrm{P}_{\mathrm{i}}^{\text {starv }}$ and hormonal responses we investigated interaction between our and relevant AtGenExpress data-sets. All AtGenExpress datasets were re-analyzed in the same manner as performed on our own. $\mathrm{P}_{\mathrm{i}}$-responsive genes were considered to be specific to $P_{i}^{\text {starv }}$ if they were not differentially regulated in any treatment regime. Hence, by determining the minimum $p$-value threshold required for each gene to be categorized as non-specific we were able to rank each $\mathrm{P}_{\mathrm{i}^{-}}$ responsive gene and determine its relative specificity. Using this method we showed that MYB72 is highly $\mathrm{P}_{\mathrm{i}^{-}}$ specific when compared to any other gene. This measure of relative specificity allowed us to determine which members of gene families play a primary role and which are functionally redundant in the $\mathrm{P}_{\mathrm{i}}$-response. Although both MYB72 and MYB74 are significantly regulated the former gene is ranked $8^{\text {th }}$ for $\mathrm{P}_{\mathrm{i}}$-specificity whereas the latter $1238^{\text {th }}$. By contrast, all the 3 cytochrome $\mathrm{P} 450$ genes (CYP94D1, ranked $13^{\text {th }}$; CYP735A1, ranked $24^{\text {th }}$; CYP76G1, ranked $27^{\text {th }}$ ) were highly specific to $\mathrm{P}_{\mathrm{i}}^{\text {starv }}$. This result suggests that they are not redundant and execute distinct functions with little overlap. We note that this 
analysis is heavily dependent on the number or breadth of treatments tested. To interpret highly $\mathrm{P}_{\mathrm{i}}$-specific genes, we have assumed the treatments selected from AtGenExpress to be an adequate sampling of biological stimuli.

In addition to specificity, we have also attempted to measure gene interaction. Highly specific genes may lose their specificity by inclusion of additional treatments to the study. On the other hand, the less specific a gene, the more interactive it becomes and the less likely it is to change when additional treatments are included in the study. Also, highly interactive $\mathrm{P}_{\mathrm{i}}$-responsive genes offer clues to $\mathrm{P}_{\mathrm{i}}$-signaling in terms of co-regulation. For instance, we have determined groups of co-regulated $\mathrm{P}_{\mathrm{i}}$-responsive genes that are influenced by one or more of the following treatments: ABA, cold, salt, drought, and $B$. cinerea infection. Indeed, these 5 treatments give the greatest degree of interactivity with $\mathrm{P}_{\mathrm{i}}^{\text {starv }}$. When compared to ABA treatment other hormone treatments such as ACC, IAA, MJ, BL, and ZEA elicit the expression of at most less than $32 \%$ of the number of $\mathrm{P}_{\mathrm{i}}$-responsive genes.

\section{Conclusion}

This study presents a genome-wide description of Arabidopsis' response and recovery to $\mathrm{P}_{\mathrm{i}}^{\text {starv }}$ for both roots and shoots. Utilizing two different technological platforms to determine transcriptome changes we found that the majority of known $\mathrm{P}_{\mathrm{i}}$-responsive genes were initially responsive. Whilst our analysis mainly focused on genes represented by probes on both micro- and tilingarray platforms we also identified 477 tiling-arrayspecific genes as being regulated by $\mathrm{P}_{\mathrm{i}}^{\text {starv }}$. One such gene was IPS1 a non-coding gene important for $\mathrm{P}_{\mathrm{i}}$ homeostasis that exhibited an initial fold-change in roots and shoots of 63 and 95, respectively. For research areas such as plant $P_{i}$ starvation, where transcriptomics studies have relied heavily on micro-array data, these results highlight the utility of true genome-wide studies in the detection of coding as well as non-coding transcript levels. All together, our results show a more varied response-and-recovery molecular phenotype than hitherto recognized in the literature. This study, which presents an initial investigation into the functional aspect of these $\mathrm{P}_{\mathrm{i}}$-responsive genes, has uncovered a progression of differentially regulated functional classes: from initially responsive ion-transporters and persistent cellular signaling genes to latently responsive transcriptional regulators. We hypothesize that initially responsive genes identified in this study function in immediate survival to $\mathrm{P}_{\mathrm{i}}$ limiting stress - transporting $\mathrm{P}_{\mathrm{i}}$ from source-to-sink whilst maintaining electrochemical gradients as indicated by the initial regulation of $\mathrm{P}_{\mathrm{i}}$ and metal-ion transporters. This hypothesis is extended to include persistently and latently responsive genes whereby we surmise that persistently responsive genes participate in the transition between survival and recovery. This transition is evidenced by the increase in differential regulation of persistently responsive genes involved in cellular signaling to those latent genes coding for transcriptional regulators. Moreover, the extent of transcriptional regulators elicited by $\mathrm{P}_{\mathrm{i}}^{\text {starv }}$ suggests the presence of regulons separate from that of the PHR1 regulon. Whether or not these regulons are $\mathrm{P}_{\mathrm{i}}^{\text {starv }}$-specific remains an open question. However, analysis of cross-talk using data generated from this study and from AtGenExpress revealed that many novel $\mathrm{P}_{\mathrm{i}}$-responsive genes identified here appear to be more specific to $\mathrm{P}_{\mathrm{i}}^{\text {starv }}$ than previously identified $\mathrm{P}_{\mathrm{i}^{-}}$ responsive regulons. Interestingly, $\mathrm{PHO} ; ; \mathrm{H1}$ - a close homolog to PHO1 with functional redundancy in $\mathrm{P}_{\mathrm{i}^{-}}$ signaling - showed less cross-talk with other treatments than PHO1, in roots. This suggests that even though PHO1 traditionally displays a greater response to $\mathrm{P}_{\mathrm{i}}^{\text {starv }}$ than PHO1;H1, the PHR1-mediated PHO1;H1 response may be more specific to $\mathrm{P}_{\mathrm{i}}^{\text {starv }}$ than the $\mathrm{PHO1}$ pathway (PHR1-independent). By applying the same reasoning to other well-known $\mathrm{P}_{\mathrm{i}}$ responsive families we observed that: 1) genes involved in the biosynthesis of galactolipids (phosolipid alternatives) in non-photosynthetic tissues - MGD2, MGD3, and DGD2 - were highly specific to $\mathrm{P}_{\mathrm{i}}$ limiting stress; 2) $\mathrm{P}_{\mathrm{i}}$ transporters PHT1;1, PHT1;3 and PHT1;7-9 (regulated by PHR1) were specific to $P_{i}^{\text {starv }}$ whereas their other family members were not. Also, PHT1;1 is regarded as one of the most responsive $\mathrm{P}_{\mathrm{i}}$ transporters to $\mathrm{P}_{\mathrm{i}}$ limitation suggesting that PHT1;1 is the primary acting member of the PHT1 family in the starvation response; 3) 3 of the 4 members in the $S P X$ family are $\mathrm{P}_{\mathrm{i}}^{\mathrm{starv}}$ specific $(S P X 1-3)$. Interestingly, SPX1-3 are under PHR1 control. Indeed, for each of the known $P_{i}$ responsive gene families mentioned, the members that we observed to be most $\mathrm{P}_{\mathrm{i}}^{\text {starv }}$-specific - PHO1; H1, PHT1;7-9, and SPX1-3 - have also been reported to be regulated by the TF PHR1. Finally, a large degree of cross-talk among clusters of co-regulated genes implicated ABA as the likely hormone mediator responsible for regulating common stress-responsive pathways; in particular cold, salt, and osmotic stress. In the future we will apply this approach to the analysis of additional treatments with the view of building a comprehensive stress response-andrecovery database.

\section{Methods}

\section{Plant material and growth conditions}

Non-sterile WT (Col-0) seeds were sowed on rock wool (Grodan Inc.) pre-soaked in basal MGRL hydroponic media $^{24}$ and cold-treated at $4^{\circ} \mathrm{C}$ for 3 days. Plants were grown at $22^{\circ} \mathrm{C}$ under $150 \mu \mathrm{mol} \mathrm{m} \mathrm{m}^{-2} \mathrm{~S}^{-1}$ fluence rate and a $12 \mathrm{hr}: 12 \mathrm{hr}$ light:dark cycle. To minimize environmental variation, plants were rotated in growth chambers once a day. In phosphate depleted media, $1.75 \mathrm{mM}$ MES 
(pH 5.8) was used instead of $1.75 \mathrm{mM}$ sodium phosphate (pH 5.8). All hydroponic media were aerated to maximize air supply during hydroponic culture. All plants were grown in basal MGRL hydroponic media for 20 days before being transferred to a phosphate-deficient medium. During the 10-day treatment, the phosphatedeficient medium was replaced every three days. For recovery experiments, plants previously grown in phosphatedeficient medium for 10 days were transferred to fullstrength MGRL medium for an additional 3 days. Samples were collected on the 10th and 13th $(10+3)$ day. Phosphate-starved shoot and root samples were collected separately at the indicated time point. Furthermore, all experiment procedures such as media replacement and sample collection were performed in the middle of day in order to minimize possible circadian effect. In parallel, control plants were grown in a full-strength MGRL media before sample collection on the 10th day after the initial 20-day growth period.

\section{Preparation of genechip and tiling-arrays}

Total RNAs extracted by RNA easy extraction kit (Qiagen) were used for Arabidopsis Genechip ATH1 and tiling arrays 1.0R (Affymetrix). Samples included three biological replicates each for mock-treatment leaves $(\mathrm{ML})$, mock-treatment roots $(\mathrm{MR}), \mathrm{P}_{\mathrm{i}}$-starvation-leaves (TL), $\quad \mathrm{P}_{\mathrm{i}}$-starvation-roots (TR), $\mathrm{P}_{\mathrm{i}}$-starvation-recovery leaves (RL), and $\mathrm{P}_{\mathrm{i}}$-starvation-recovery roots (RR). Probes of all 36 samples were synthesized as previously described ${ }^{25,26}$. The efficiency of biotin labeling was confirmed by Gel-shift assay with NeutrAvidin (Pierce) as described in Genechip Whole transcript (WT) double-stranded target assay manual (Affymetrix). Hybridization and scanning of all arrays were done at the Genomics Resource Center in the Rockefeller University following the manufacturer's instructions (Affymetrix).

\section{Detection of phosphate responsive genes}

Semi-quantitive RT-PCR and real-time PCR were performed to confirm expression changes of selective genes uncovered by gene/tiling arrays. Typically, $1 \mu \mathrm{g}$ total RNA prepared by Qiagen RNA column extraction including DNase treatment (Qiagen) was used as a template for reverse transcription (Superscript III RT-PCR, Invitrogen). First strand cDNA was synthesized with an oligo dT primer or with an strand-specific primer. In parallel, actin transcript was used as an internal loading control and same amount of RNA without reverse transcription as a negative control. $100 \mathrm{ng}$ of single strand cDNA were used to quantify expression by real-time PCR (Bio-Rad CFX96). Each $\Delta C(\mathrm{t})$ value and relative expression of phosphate-responsive genes was determined by Bio-Rad CFX manager program (Bio-Rad).

\section{Description of gene lists}

Below is a description of the pertinent gene lists mentioned in this work.

General statistics (based on transcript levels):

1. 1.1257 Affymetrix probe-sets differentially expressed in roots.

2. 182 Affymetrix probe-sets differentially expressed in shoots.

3. 89 Affymetrix probe-sets commonly regulated in roots and shoot.

4. 1350 Affymetrix probe-sets identified in total (root + shoot - common).

Functional analysis (based on one-to-one relationships for terms and AGI identifiers):

5. 84 AGI identifiers previously known as Pi responsive. 6. 1231 AGI identifiers in root response, excluding the 84 previously identified.

Cross-talk analysis (based on transcript levels):

7. 1249 Affymetrix probe-sets differentially expressed in roots.

a. a.1257 minus 8 Affymetrix probe-sets which were ambiguously mapped to AGI identifiers and discarded from further analysis.

\section{Bioinformatics}

The accession code, GSE34004, may be used to access the micro- and tiling-array data from the Gene Expression Omnibus (GEO). The computational portions of the Materials and Methods are described in Additional file 9. This file includes descriptions of the: analysis pipeline; experimental design; quality control; normalization; gene classification; analysis of functional annotations; and analysis of $P_{i}^{\text {starv }}$ specificity and cross-talk.

\section{Additional files}

Additional file 1: Inter-study comparison, is a figure detailing a comparison of genes identified by various research groups to be regulated by phosphate flux.

Additional file 2: Response and recovery (eBayes), contains statistical data generated from the ebayes function in the Limma package ( $R$, statistical environment) for the response and recovery in both roots and shoots.

Additional file 3: qRT-PCR, is a figure displaying qRT-PCR results for 37 loci from the top differentially expressed genes known to respond to phosphate-starvation.

Additional file 4: $\mathrm{P}_{\mathrm{i}}$ marker genes, $\mathrm{RT}$-PCR of $\mathrm{P}_{\mathrm{i}}$-starvation responsive non-coding RNAs IPS, miR399, and miR827 at 10-days $\mathrm{P}_{\mathrm{i}}$-replete and -starved, and 3-days recovery. 
Additional file 5: Expression profiles for 5,044 genes undetectable by the ATH1 micro-array platform, a table describing the response and recovery of said 5,044 genes to $\mathrm{Pi}$ starvation in both root and shoot.

Additional file 6: Literature survey references, additional references used in the determination of the $\mathbf{8 4}$ known Pi-responsive gene-set.

Additional file 7: Gene response and recovery class list, categorizes genes into 1 of 9 response-and-recovery classes for roots and shoots, separately.

Additional file 8: Textmining data, is a table providing the data we collected and used to mine the text resources annotated by TAIR for each locus.

Additional file 9: Materials and methods for Bioinformatics, the computational portion of the materials and methods section.

Additional file 10: $P_{i}$-specifity rankings, is a table summarizing results for loci that we were able to assign a ranking of phosphate-specificity.

\section{Abbreviations}

$P_{i}$ : phosphate; $P_{i}^{\text {starv }}: P_{i}$ starvation; $P_{i}^{\text {mock. }}$ mock treatment; $P_{i}^{\text {replete. }} P_{i}$ replete; PC: principal components; BAR: Basal Response; IPR: Initial Positive Response; INR: Initial Negative Response; PPR: Persistent Positive Response;

PNR: Persistent Negative Response; LPR: Latent Positive Response;

LNR: Latent Negative Response; CPR: Continuous Positive Response;

CNR: Continuous Negative Response; RR: Root Response; SR: Shoot Response.

Competing interests

The authors declare that they have no competing interests.

\section{Author's contributions}

The experimental design was conceived by JW, TK, MH, and NHC and all experiments were performed by JW except the computational analysis. Data was analyzed by CRM with assistance from JL, HW, XJW, and VBB. This paper was written by JW, CRM, VBB, and NHC. All authors read and approved the final manuscript.

\section{Acknowledgements}

This work was supported in part by a grant from Bayer Crop Sciences.

\section{Author details}

'Laboratory of Plant and Molecular Biology, The Rockefeller University, New York 10065, NY, USA. ²Bayer Crop Science, Technologiepark 38, 9052, Ghent, Belgium. ${ }^{3}$ State Key Laboratory of Plant Genomics, Institute of Genetics and Developmental Biology, Chinese Academy of Sciences, Beijing 100101, China. ${ }^{4}$ Computational Bioscience Research Center (CBRC), King Abdullah University of Science and Technology (KAUST), Thuwal, Kingdom of Saudi Arabia.

Received: 2 December 2011 Accepted: 10 April 2012

Published: 3 May 2012

\section{References}

1. Raghothama KG: Phosphate Acquisition. Annual Review of Plant Physiology and Plant Molecular Biology 1999, 50:665-693.

2. Schachtman DP, Reid RJ, Ayling S: Phosphorus Uptake by Plants: From Soil to Cell. Plant Physiology 1998, 116:447-453.

3. Vance $\mathrm{CP}$, Uhde-Stone $\mathrm{C}$, Allan DL: Phosphorus acquisition and use: critical adaptations by plants for securing a nonrenewable resource. New Phytologist 2003, 157:423-447.

4. Ma W, Ma L, Li J, Wang F, Sisak I, Zhang F: Phosphorus flows and use efficiencies in production and consumption of wheat, rice, and maize in China. Chemosphere 2011, 84:814-821.

5. MacDonald GK, Bennett EM, Potter PA, Ramankutty N: Agronomic phosphorus imbalances across the world's croplands. Proc Natl Acad Sci U S A 2011, 108:3086-3091.

6. Chebud Y, Naja GM, Rivero R: Phosphorus run-off assessment in a watershed. J Environ Monit 2011, 13:66-73.

7. Howarth R, Sharpley A, Walker D: Sources of nutrient pollution to coastal waters in the United States: Implications for achieving coastal water quality goals. Estuaries and Coasts 2002, 25:656-676.
8. Moss B: Water pollution by agriculture. Philos Trans R Soc Lond B Biol SCi 2008, 363:659-666

9. Misson J, Raghothama KG, Jain A, Jouhet J, Block MA, Bligny R, Ortet $P$, Creff A, Somerville S, Rolland N, et al: A genome-wide transcriptional analysis using Arabidopsis thaliana Affymetrix gene chips determined plant responses to phosphate deprivation. Proc Natl Acad Sci U S A 2005, 102:11934-11939.

10. Morcuende R, Bari R, Gibon Y, Zheng W, Pant BD, BIÄSing O, Usadel B, Czechowski T, Udvardi MK, Stitt M, Scheible W-R: Genome-wide reprogramming of metabolism and regulatory networks of Arabidopsis in response to phosphorus. Plant Cell Environ 2007, 30:85-112.

11. Muller R, Morant M, Jarmer $H$, Nilsson L, Nielsen TH: Genome-wide analysis of the Arabidopsis leaf transcriptome reveals interaction of phosphate and sugar metabolism. Plant Physiol 2007, 143:156-171.

12. Nilsson $L$, Muller $R$, Nielsen $T H$ : Dissecting the plant transcriptome and the regulatory responses to phosphate deprivation. Physiol Plant 2010, 139:129-143.

13. Bustos R, Castrillo G, Linhares F, Puga Ml, Rubio V, Perez-Perez J, Solano R, Leyva A, Paz-Ares J: A central regulatory system largely controls transcriptional activation and repression responses to phosphate starvation in Arabidopsis. PLoS Genet 2010, 6(9). pii: e1001102.

14. Thibaud M, Arrighi J, Bayle V, Chiarenza S, Creff A, Bustos R, Paz-Ares J, Poirier $Y$, Nussaume L: Dissection of local and systemic transcriptional responses to phosphate starvation in Arabidopsis. Plant J 2010, 64(5):775-89.

15. Ji H, Jiang $H$, Ma W, Johnson DS, Myers RM, Wong WH: An integrated software system for analyzing ChIP-chip and ChIP-seq data. Nat Biotech 2008, 26:1293-1300.

16. Saeed Al, Bhagabati NK, Braisted JC, Liang W, Sharov V, Howe EA, Li J, Thiagarajan M, White JA, Quackenbush J: TM4 microarray software suite. Methods Enzymol 2006, 411:134-193.

17. Saeed Al, Sharov V, White J, Li J, Liang W, Bhagabati N, Braisted J, Klapa M, Currier T, Thiagarajan M, et al: TM4: a free, open-source system for microarray data management and analysis. Biotechniques 2003, 34:374-378

18. Zhang H, Forde BG: An Arabidopsis MADS Box Gene That Controls Nutrient-Induced Changes in Root Architecture. Science 1998, 279:407-409.

19. de Folter S, Immink RGH, Kieffer M, Parenicová L, Henz SR, Weigel D, Busscher M, Kooiker M, Colombo L, Kater MM, et al: Comprehensive Interaction Map of the Arabidopsis MADS Box Transcription Factors. The Plant Cell Online 2005, 17:1424-1433.

20. Zhong R, Lee C, Zhou J, McCarthy RL, Ye Z-H: A Battery of Transcription Factors Involved in the Regulation of Secondary Cell Wall Biosynthesis in Arabidopsis. The Plant Cell Online 2008, 20:2763-2782.

21. Zhou J, Lee C, Zhong R, Ye Z-H: MYB58 and MYB63 Are Transcriptional Activators of the Lignin Biosynthetic Pathway during Secondary Cell Wall Formation in Arabidopsis. The Plant Cell Online 2009, 21:248-266.

22. Wilson K, Long D, Swinburne J, Coupland G: A Dissociation Insertion Causes a Semidominant Mutation That Increases Expression of TINY, an Arabidopsis Gene Related to APETALA2. The Plant Cell Online 1996, 8:659-671

23. Franco-Zorrilla JM, Martín AC, Leyva A, Paz-Ares J: Interaction between Phosphate-Starvation, Sugar, and Cytokinin Signaling in Arabidopsis and the Roles of Cytokinin Receptors CRE1/AHK4 and AHK3. Plant Physiology 2005, 138:847-857.

24. Qin F, Sakuma Y, Tran L-SP, Maruyama K, Kidokoro S, Fujita Y, Fujita M, Umezawa T, Sawano Y, Miyazono K-i, et al: Arabidopsis DREB2A-Interacting Proteins Function as RING E3 Ligases and Negatively Regulate Plant Drought Stress-Responsive Gene Expression. The Plant Cell Online 2008, 20:1693-1707

25. Albrecht V, Ritz O, Linder S, Harter K, Kudla J: The NAF domain defines a novel protein-protein interaction module conserved in $\mathrm{Ca2}+-$ regulated kinases. EMBO J 2001, 20:1051-1063.

26. Nelson DC, Flematti GR, Riseborough J-A, Ghisalberti EL, Dixon KW, Smith SM: Karrikins enhance light responses during germination and seedling development in Arabidopsis thaliana. Proceedings of the National Academy of Sciences 2010, 107:7095-7100.

27. Despres C, DeLong C, Glaze S, Liu E, Fobert PR: The Arabidopsis NPR1/ NIM1 protein enhances the DNA binding activity of a subgroup of the TGA family of bZIP transcription factors. Plant Cell 2000, 12:279-290. 
28. Uno Y, Furihata T, Abe H, Yoshida R, Shinozaki K, Yamaguchi-Shinozaki $\mathrm{K}$ : Arabidopsis basic leucine zipper transcription factors involved in an abscisic acid-dependent signal transduction pathway under drought and high-salinity conditions. Proc Natl Acad Sci U S A 2000, 97:11632-11637

29. Zhang L-Y, Bai M-Y, Wu J, Zhu J-Y, Wang H, Zhang Z, Wang $W$, Sun $Y$, Zhao J, Sun $X$, et al: Antagonistic HLH/bHLH Transcription Factors Mediate Brassinosteroid Regulation of Cell Elongation and Plant Development in Rice and Arabidopsis. The Plant Cell Online 2009, 21:3767-3780.

30. Pandey SP, Somssich IE: The Role of WRKY Transcription Factors in Plant Immunity. Plant Physiology 2009, 150:1648-1655.

31. Jung K-H, Seo Y-S, Walia H, Cao P, Fukao T, Canlas PE, Amonpant F, BaileySerres J, Ronald PC: The Submergence Tolerance Regulator Sub1A Mediates Stress-Responsive Expression of AP2/ERF Transcription Factors. Plant Physiology 2010, 152:1674-1692.

32. Yang C-Y, Hsu F-C, Li J-P, Wang N-N, Shih M-C: The AP2/ERF Transcription Factor AtERF73/HRE1 Modulates Ethylene Responses during Hypoxia in Arabidopsis. Plant Physiology 2011, 156:202-212

33. Ascencio-lbáñez JT, Sozzani R, Lee T-J, Chu T-M, Wolfinger RD, Cella R, Hanley-Bowdoin L: Global Analysis of Arabidopsis Gene Expression Uncovers a Complex Array of Changes Impacting Pathogen Response and Cell Cycle during Geminivirus Infection. Plant Physiology 2008, 148:436-454.

34. Wang Y, Zhang W-Z, Song L-F, Zou J-J, Su Z, Wu W-H: Transcriptome Analyses Show Changes in Gene Expression to Accompany Pollen Germination and Tube Growth in Arabidopsis. Plant Physiology 2008, 148:1201-1211.

35. Oono Y, Seki M, Satou M, lida K, Akiyama K, Sakurai T, Fujita M, YamaguchiShinozaki K, Shinozaki K: Monitoring expression profiles of $<i>$ Arabidopsis genes during cold acclimation and deacclimation using DNA microarrays. Functional \& Integrative Genomics 2006, 6:212-234.

36. Hanada K, Sawada Y, Kuromori T, Klausnitzer R, Saito K, Toyoda T, Shinozak K, Li W-H, Hirai MY: Functional Compensation of Primary and Secondary Metabolites by Duplicate Genes in Arabidopsis thaliana. Molecular Biology and Evolution 2011, 28:377-382.

37. Lee J-Y, Colinas J, Wang JY, Mace D, Ohler U, Benfey PN: Transcriptional and posttranscriptional regulation of transcription factor expression in Arabidopsis roots. Proceedings of the National Academy of Sciences 2006, 103:6055-6060.

38. Osuna D, Usadel B, Morcuende R, Gibon Y, Bläsing $O E$, Höhne M, Günter $M$, Kamlage B, Trethewey R, Scheible W-R, Stitt M: Temporal responses of transcripts, enzyme activities and metabolites after adding sucrose to carbon-deprived Arabidopsis seedlings. The Plant Journal 2007, 49:463-491.

39. Ramel F, Sulmon C, Cabello-Hurtado F, Taconnat L, Martin-Magniette M-L, Renou J-P, El Amrani A, Couee I, Gouesbet G: Genome-wide interacting effects of sucrose and herbicide-mediated stress in Arabidopsis thaliana: novel insights into atrazine toxicity and sucrose-induced tolerance. BMC Genomics 2007, 8:450.

40. Journot-Catalino N, Somssich IE, Roby D, Kroj T: The Transcription Factors WRKY11 and WRKY17 Act as Negative Regulators of Basal Resistance in Arabidopsis thaliana. The Plant Cell Online 2006, 18:3289-3302.

41. Rubio V, Linhares F, Solano R, Martin AC, Iglesias J, Leyva A, Paz-Ares J: A conserved MYB transcription factor involved in phosphate starvation signaling both in vascular plants and unicellular algae. Genes Dev 2001, 15(16):2122-33.

42. Franco-Zorrilla JM, Valli A, Todesco M, Mateos I, Puga MI, Rubio-Somoza I, Leyva A, Weigel D, Garcia JA, Paz-Ares J: Target mimicry provides a new mechanism for regulation of microRNA activity. Nat Genet 2007, 39 (8):1033-7.

43. Cheng Y, Zhou W, El Sheery NI, Peters C, Li M, Wang X, Huang J: Characterization of the Arabidopsis glycerophosphodiester phosphodiesterase (GDPD) family reveals a role of the plastid-localized AtGDPD1 in maintaining cellular phosphate homeostasis under phosphate starvation. Plant J 2011, 66(5):781-95.

44. Essigmann B, Guler S, Narang RA, Linke D, Benning C: Phosphate availability affects the thylakoid lipid composition and the expression of SQD1, a gene required for sulfolipid biosynthesis in Arabidopsis thaliana. PNAS 1998, 95(4):1950-5
45. Cruz-Rumirez A, Oropeza-Aburto A, Razo-Hernandez F, Ramirez-Chavez E, Herrera-Estrella L: Phospholipase DZ2 plays an important role in extraplastidic galactolipid biosynthesis and phosphate recycling in Arabidopsis roots. Genes Dev 2006, 103(17):6765-70.

46. Williamson LC, Ribrioux SP, Fitter AH, Leyser HM: Phosphate availability regulates root system architecture in Arabidopsis. Plant Physiol 2001, 126 (2):875-82.

47. Tominaga R, Iwata M, Sano R, Inoue K, Okada K, Wada T: Arabidopsis CAPRICE-LIKE MYB 3 (CPL3) controls endoreduplication and flowering development in addition to trichome and root hair formation. Development 2008, 135(7):1335-45.

48. Lelandais-Brière $C$, Jovanovic $M$, Torres GAM, Perrin $Y$, Lemoine $R$, CorreMenguy F, Hartmann C: Disruption of AtOCT1, an organic cation transporter gene, affects root development and carnitine-related responses in Arabidopsis. The Plant Journal 2007, 51:154-164.

49. Bari R, Datt Pant B, Stitt M, Scheible W-R: PHO2, MicroRNA399, and PHR1 Define a Phosphate-Signaling Pathway in Plants. Plant Physiology 2006, 141:988-999.

50. Rouached H, Arpat A, Poirier Y: Regulation of phosphate starvation responses in plants: signaling players and cross-talks. Mol Plant 2010, 3 (2):288-99.

51. Dello loio R, Linhares FS, Scacchi E, Casamitjana-Martinez E, Heidstra R, Costantino P, Sabatini S: Cytokinins Determine Arabidopsis Root-Meristem Size by Controlling Cell Differentiation. Current Biology 2007, 17:678-682

52. Okushima Y, Fukaki H, Onoda M, Theologis A, Tasaka M: ARF7 and ARF19 regulate lateral root formation via direct activation of LBD/ASL genes in Arabidopsis. Plant Cell 2007, 19:118-130.

doi:10.1186/1471-2229-12-62

Cite this article as: Woo et al:: The response and recovery of the Arabidopsis thaliana transcriptome to phosphate starvation. BMC Plant Biology 2012 12:62

\section{Submit your next manuscript to BioMed Central and take full advantage of:}

- Convenient online submission

- Thorough peer review

- No space constraints or color figure charges

- Immediate publication on acceptance

- Inclusion in PubMed, CAS, Scopus and Google Scholar

- Research which is freely available for redistribution 